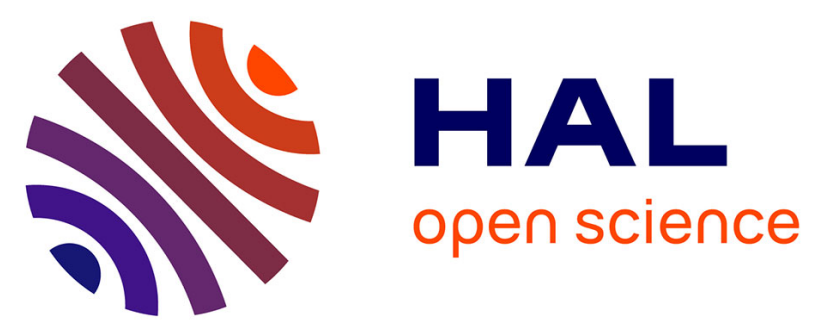

\title{
Mechanical vs. chemical stability of sulphide-based solid-state batteries. Which one is the biggest challenge to tackle? Overview of solid-state batteries and hybrid solid state batteries
}

Léa Rose Mangani, Claire Villevieille

\section{To cite this version:}

Léa Rose Mangani, Claire Villevieille. Mechanical vs. chemical stability of sulphide-based solidstate batteries. Which one is the biggest challenge to tackle? Overview of solid-state batteries and hybrid solid state batteries. Journal of Materials Chemistry A, 2020, 8 (20), pp.10150-10167. 10.1039/D0TA02984J . hal-03119503

\author{
HAL Id: hal-03119503 \\ https://hal.science/hal-03119503
}

Submitted on 24 Jan 2021

HAL is a multi-disciplinary open access archive for the deposit and dissemination of scientific research documents, whether they are published or not. The documents may come from teaching and research institutions in France or abroad, or from public or private research centers.
L'archive ouverte pluridisciplinaire HAL, est destinée au dépôt et à la diffusion de documents scientifiques de niveau recherche, publiés ou non, émanant des établissements d'enseignement et de recherche français ou étrangers, des laboratoires publics ou privés. 


\title{
ARTICLE
}

\section{Mechanical vs. chemical stability of sulphide-based solid-state- batteries. Which one is the biggest challenge to tackle? Overview of solid-state batteries and hybrid solid state batteries.}

Received 00th January 20xx, Accepted 00th January 20xx DOI: $10.1039 / x 0 \times x 00000 x$

\author{
Léa Rose Mangani, ${ }^{a}$ Claire Villevieille *a,b
}

\begin{abstract}
Solid state batteries using sulphide-based solid electrolyte materials are believed to be the ideal solution for the next generation electrochemical energy storage. A deeper investigation of those systems revealed several challenges to be tackled or at least buffered to hope for a future commercialisation. Among them, we reported the interfacial one and the mechanical one. For the former, several solutions were proposed and adapted from the knowledge acquired in the Li-ion technology. For the latter, it was only sporadicaly studied but it reveals a real challenge for solid state batteries since mechanical know-how (implying wettability process on solid) was not really acquired in conventionnal Li-ion batteries and thus solutions from scratch need to be developed. Based on the aforementionned issues, it seems logical to develop hybrid solid state batteries (combining polymer electrolyte and solid state electrolyte) to ensure a future development of solid state technology.
\end{abstract}

Solid state batteries are believed to be the next breakthrough technology in term of energy storage system owing to their safety and energy density (if successfully coupled to Li metal). ${ }^{1-4}$ Several families of solid electrolytes (SE) are reported in the literature among them the oxide, the thiophosphates, the polymers, the sulphides and many others as reported in the very recent review of Ohno et al. ${ }^{5}$. To date, the most investigated ones rely on amorphous glass (mostly LiP-S based) and the one relaying on ceramic (Li-La-Zr-O based). ${ }^{6}$ The formers have the advantage to be sintered at room temperature and are obtained through a relatively easy synthesis at low temperature (less than $\left.300^{\circ} \mathrm{C}\right)^{7,} 8$ but the synthesis and cell assembly have to be performed with lot of care due to the high reactivity of Li-P-S family with air and moisture leading to release of toxic $\mathrm{H}_{2} \mathrm{~S}$ gas. ${ }^{9}, 10$ For the latter, they have the advantage to be relatively stable in the air/moisture environment (carbonate formation is expected at the surface), but their sintering is a real challenge since it has to be performed at high temperature $\left(>1000^{\circ} \mathrm{C}\right)$ with a constant $\mathrm{Li}$ supply to keep their good ionic conductivity. ${ }^{11}$ From engineering point of view, it seems that the thiosulfate solid electrolytes are easier to process whereas the ceramic ones are more targeted for thin films deposition ${ }^{12}$, avoiding partially the high temperature sintering process. Based on this fact, we focused this review only on the investigation of sulphide-based solid electrolyte and their derivatives.

\footnotetext{
a. Université Grenoble-Alpes, Grenoble INP, LEPMI Laboratory, 1130 Rue de la Piscine, 38402 Saint Martin d'Hères, France.

b. Univ. Grenoble Alpes, CEA, CNRS, IRIG, SyMMES, 17 rue des Martyrs, 38054 Grenoble, France

Email : claire.villevieille@gmail.com
}

This family of materials is rather broad, and lot of research are still ongoing to improve their ionic conductivity. ${ }^{7,} 13$ Table 1 is summarizing the most common sulphide-based solid electrolyte existing along with their reported ionic conductivity, even if some debates start to rise from the literature as recently reported ${ }^{14}$. Several synthetic routes can be used to develop sulphide-based solid electrolyte, among them the solid state one and the solution-based one. The synthesis route employed has generally consequences on the purity of the phase as well as the local order/disordered known to influence the ionic conductivity of the obtained electrolytes. In the literature, mostly two main approaches are used to develop the sulphidebased electrolytes, the ones where the materials are obtained only through ball milling and that delivers ionic conductivity of ca. 0.1-1 mS/cm, and the others that are obtained through ball milling synthesis followed by another crystallisation step at high temperature presenting very attractive ionic conductivity around $10 \mathrm{mS} / \mathrm{cm}$. Unfortunately, the solid-state routes are known to generate more inhomogeneity due to the poor dispersion of the reactants prior to calcination. Thus, solutionbased syntheses are generally preferred for a better tuning of the particle size, homogeneity and investigation of structural/electro-chemico-physical properties such as ionic conductivity, sintering and electrochemical performance. A recent review by Ghidiu et al. is summarizing the different solution-based routes existing to tune the solid electrolyte synthesis $^{15}$. A typical example of the impact of the synthesis condition onto the ionic conductivity of the argyrodites solid electrolyte is given in the paper of Gautam et al. ${ }^{16}$. In this paper, the authors demonstrated that the ionic conductivity of sulphide-based solid electrolytes can be tuned by changing the local structural disorder depending on the cooling stage. Additionally, they demonstrated that ball milling synthesis is a 
crucial step as it can already initiate an intimal mixture of the precursors reducing then the calcination time.

To date, the most attractive sulphide-based solid electrolytes are obtained through high temperature synthesis which is difficult to scale up since it requires a sealed tube process or close container to control the sulfur/phosphorus evaporation and their toxic reaction if they are in contact with air and moisture (phosphine and $\mathrm{H}_{2} \mathrm{~S}$ ). ${ }^{9}, 10$

\begin{tabular}{|c|c|c|c|}
\hline Materials & Short name & Synthesis & Ionic conductivity \\
\hline \multirow{5}{*}{$\begin{array}{c}L_{3} P S_{4} \\
L i_{10} G e P_{2} S_{12} \\
L i_{7} P_{3} S_{11} \\
L i_{6} P S_{5} C l\end{array}$} & LPS & BM & $0.2 \mathrm{~ms} / \mathrm{cm}^{17,} 18$ \\
\hline & LGPS & $\mathrm{BM}+\mathrm{HT}_{500}$ & $12 \mathrm{~ms} / \mathrm{cm}^{8}$ \\
\hline & L7PS & $\mathrm{BM}+\mathrm{HT}_{250}$ & $17 \mathrm{~ms} / \mathrm{cm}^{19,20}$ \\
\hline & LPSCI & $\mathrm{BM}\left(+\mathrm{HT}_{550}\right)$ & $1.3 \mathrm{~ms} / \mathrm{cm}^{21}$ \\
\hline & LSPS & $B M+H T_{600}$ & $7 \mathrm{~ms} / \mathrm{cm}^{22}$ \\
\hline
\end{tabular}

Table 1. Summary of the sulphide-based solid electrolytes reported in the literature. RT stands for room temperature, BM for ball milling and $\mathrm{HT}$ for high temperature synthesis. The subscript number close to HT indicates the synthesis temperature.

As such the ionic conductivities of sulphide-based solid electrolytes are close to the one of organic-based liquid electrolyte and the materials can be sintered at room temperature, two important conditions fulfilled to test them as solid electrolyte in battery configuration. To this point, VargasBarbosa and Roling investigated the charge and mass transport properties in liquid and solid electrolyte ${ }^{23}$. Using the Onsager linear irreversible thermodynamic theory, they demonstrated that the transference number of the solid electrolyte is very close to 1 , which is optimal for the fast charging condition, giving one reason more top hope for commercialization of solidstate batteries.

Unfortunately, several challenges remained to date as all scientific reports expressed the needs to investigate better the processes occurring in sulphide-based solid state batteries especially i) the sintering process and engineering process (manufacture process) ${ }^{24-26}$, ii) the interfacial issues $27-31$ and iii) the mechanical stability 32,33 . In this review, we discuss the recent progress made in the investigation of the interfacial issues and mechanical issues as well as the possible solution existing to tackle them both.

\section{Interfacial issues}

Interfacial issues are always a weak point when it comes to conventional Li-ion batteries but even more for solid-state batteries. Indeed, to ensure proper electrochemical cycling, the porosity in solid state batteries should be at minima in the separator (composed solely of dense pellet of SE) and in the composite electrode (mixture of SE coupled to the active materials and possibility a conductive agent). As the sulphidebased solid electrolyte can be sintered at room temperature, the binder is generally unnecessary in this configuration. There are two main interfaces in the solid-state batteries, the one in between the solid electrolyte and the Li metal/composite electrode (so called here EEI for electrolyte-electrode-interface) and the one between the active materials and the solid electrolyte (and the conductive agent if needed) inside the composite electrode ( $\mathrm{ECl}$, so called electrolyte-compositeinterface) (Figure 1). In both cases, chemical and mechanical stability are intrinsically linked, and both will be critical to ensure proper electrochemical cycling but not for the same reasons. For the EEI one, the chemical stability will play a major role since we must have a chemical affinity between the solid electrolyte and the Li metal to ensure optimal cycling but in the top of it, the mechanical factor will be also a key parameter to control because the surface area contact between the two layers is very high and small nanometre gaps between the layers will lead to inhomogeneous current density distribution across this interface generating battery failure. For the $\mathrm{ECl}$ one, the chemical stability will be crucial as the specific area contact between the two (three) electrode components will be maximised, thus chemical affinity between the component is determining the success of the battery. However, the contact between the components should be excellent as it will ensure an optimal wettability of the composite electrode while keeping in a proper way, the electronic and ionic conductivity through the electrode. Unfortunately, the mechanical stability will be caused by the charge/discharge process generating electrode breathing (due to the volume changes) leading to fractures appearing in the composite electrode changing the tortuosity factor and enhancing the inhomogeneous current distribution across the electrode. Through this review, we will report the last results obtained in the optimisation of the mechanical and interfacial issues related to solid-state batteries.
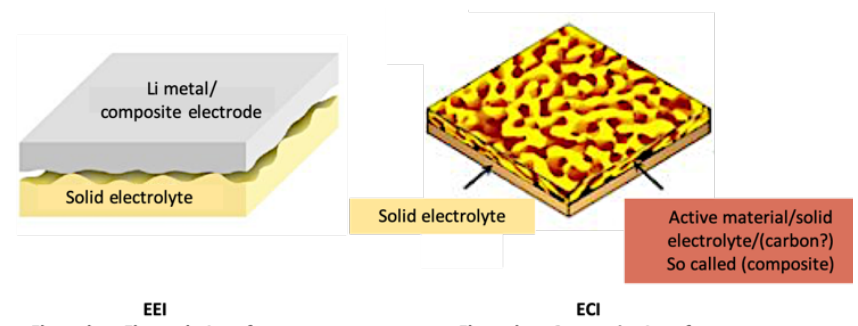

Figure 1. Scheme about the two possible interfaces existing in solid state batteries. Adapted from ref. ${ }^{34}$ (left, CC BY-NC 4.0) and ref. ${ }^{35}$ (right, Creative Commons Attribution 3.0 unported License).

\section{Reduction/oxidation of the solid electrolyte alone}

As already reported in the literature, the theoretical electrochemical stability window of the sulphide-based solid electrolyte is very narrow ${ }^{36}$ meaning that the solid electrolytes will be then reduced and oxidised after each cycle generating decomposition products. Recently, Dewald et al. demonstrated that experimentally this stability window is larger, going up to $3.1 \mathrm{~V} \mathrm{vs}$. $\mathrm{Li}^{+} / \mathrm{Li}$ but still lower than most of the commercialized cathodes ${ }^{36,37}$, even if efforts are made also to improve the solid electrolyte stability ${ }^{38,} 39$. This sub-chapter will discuss the oxidation of the solid electrolyte, as the reduction will be discussed in the next sub-chapter. 
Several characterizations techniques were employed to investigate the mechanisms being the oxidation/reduction of the solid electrolyte. Dietrich et al used X-ray photoelectron spectroscopy (XPS) and X-ray absorption spectroscopy (XAS) to monitor the interfacial reaction in sulphide-based solid electrolyte ${ }^{40}$. By combining the results obtained from the sulfur $\mathrm{K}$ - and L-edge and the XPS data of various LPS materials, they demonstrated that the LPS structure is evolving and that several structural clusters could be formed, some of them being detrimental for cycling whereas other could be cycled reversible giving a nice guideline about the interfacial processes occurring in LPS materials. Using the concept of useful decomposition products, Han et al. operated a single battery material where LGPS was used as the solid electrolyte but also as positive and negative electrode if carbon was added to the composite electrode $^{41}$. The goal was to tackle the problem of high interfacial resistances existing between the electrode active materials and in the EEI. Since the decomposition products are $\mathrm{S}$ and $\mathrm{GeS}_{2}$, they can be used as active redox centre. The former is known to react with lithium to generate $\mathrm{Li}_{2} \mathrm{~S}$ (cathode material) and the latter will also react with $\mathrm{Li}$ to create $\mathrm{Li}_{15} \mathrm{Ge}_{4}$ (anode material). Despite having better interfacial contact (as demonstrated by electrochemical impedance spectroscopy), the electrochemical performance reported were rather poor in such system because of the breathing of the electrode during cycling generating mechanical failure. Recently, Tan et al. presented a similar study for LPSCl solid electrolyte by investigating the reversible processes occurring during cycling ${ }^{42}$. They demonstrated impressive reversibility of the electrochemical processes when the cell Li-In/LPSCI/LPSCI-C is cycled. The explanation behind this mechanism lied on Figure 2. During oxidation and reduction, several decomposition products are generated such as $\mathrm{Li}_{2} \mathrm{~S}, \mathrm{Li}_{3} \mathrm{P}, \mathrm{LiCl}, \mathrm{S}, \mathrm{P}_{2} \mathrm{~S}_{5}$ etc...quite often harmful for proper electrochemical cycling ${ }^{43}$. The important point here is to use the intermediate decomposition products as active centre showing the reversibility of the process. Once the solid electrolyte is oxidized in $\mathrm{S}$ and $\mathrm{P}_{2} \mathrm{~S}_{5}$, the following reduction leads to an intermediate phase $\mathrm{Li}_{3} \mathrm{PS}_{4}$. The further reduction of this phase generates $\mathrm{Li}_{2} \mathrm{~S}$ and $\mathrm{Li}_{3} \mathrm{P}$, and the following oxidation of the pre-cited components leads again to $\mathrm{Li}_{3} \mathrm{PS}_{4}$, a stable intermediate phase responsible of the nice reversibility of the cell. On top of this, the authors demonstrated that during oxidation of the $\mathrm{SE}$, the decomposition products are strongly influencing the impedance response and the overall polarisation leading to accelerate battery failure, whereas the decomposition products generated during reduction have little influence on the impedance, thus on cycling. These results indicate that the cathode interfacial properties are more difficult to control that the one at the negative electrode and that special care need to be taken in the cathode electrode engineering to ensure proper electrochemical cycling.

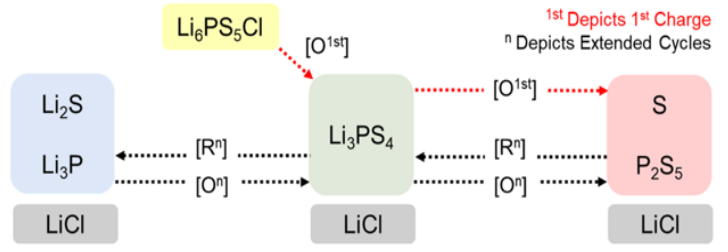

Figure 2. Redox reaction pathway of $\mathrm{Li}_{6} \mathrm{PS}_{5} \mathrm{Cl}$ for the first charge and subsequent cycles. Reprinted with permission from ref. ${ }^{42}$. Copyright (2020) American Chemical Society.

\section{Positive electrode interface (oxidation of the solid electrolyte)}

Auvergniot et al. investigated the interfacial stability of the LPSCl solid electrolyte in contact with several cathode materials (namely, $\mathrm{LiCoO}_{2}$ (hereafter called LCO), $\mathrm{LiNi}_{1 / 3} \mathrm{Co}_{1 / 3} \mathrm{Mn}_{1 / 3} \mathrm{O}_{2}$ (hereafter called NCM111) and $\mathrm{LiMn}_{2} \mathrm{O}_{4}$ (hereafter called LMO)) using X-ray photoemission spectroscopy (XPS) and Auger electron spectroscopy ${ }^{44}$. They found out that the solid electrolyte is indeed unstable at potential higher than $2.5 \mathrm{~V}$ vs. $\mathrm{Li}^{+} / \mathrm{Li}$. Also, they demonstrated that even if the decomposition products obtained during cycling are the same whatever the cathode used, the electrochemical results are different due to the depth of decomposition in the composite electrode which is not the same. For LCO cathode, the electrochemical fading is important since after 25 cycles, half of the experimental specific capacity is lost. The XPS analysis revealed the presence of several decomposition products coming from the SE such as elemental sulfur, lithium polysulfides, $\mathrm{LiCl}$ and also some phosphates most probably coming from the decomposition of LCO particles at high voltage generating oxidation in the system. Additionally, by performing mechanical etching, they found out that the electrochemical processes are not homogeneous since the proportion of the decomposition products are not the same at the cathode/electrolyte interface, in the bulk of the composite electrode or at the current collector side, which indicates a lack of electronic/ionic conductivity. $\mathrm{Xu}$ et al. performed a similar investigation on LCO vs $\operatorname{InLi} \mathrm{i}_{x}$ (with standard LPS electrolyte) using operando XPS measurement. ${ }^{45}$ They detected the oxidation of the solid electrolyte at potential higher than $2.8 \mathrm{~V}$ vs. $\mathrm{Li}^{+} / \mathrm{Li}$ with similar by-products as the one reported by Auvergniot et al. ${ }^{44}$. Additionally, they demonstrated that the decomposition products are partially reversible leading to extra charge capacity in the electrode material. Raman imaging technique was also employed to follow the delithiation of LCO in contact with LPS solid electrolyte ${ }^{46}$. Otoyama et al. demonstrated that the delithiation of LCO is not homogeneous ${ }^{46}$. They made a correlation between the big LCO aggregates which are not in contact with the SE and thus not wetted properly leading to electrochemically inactive particle. At the opposite, the ones close to the SE are overcharged resulting in the formation of $\mathrm{CO}_{3} \mathrm{O}_{4}$, an irreversible product generating battery failure. This result indicates again that a particular care has to be taken to prepare the composite electrode materials. 
(a)

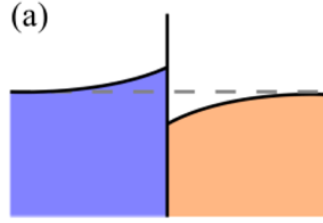

$\mathrm{LCO}$ (b)

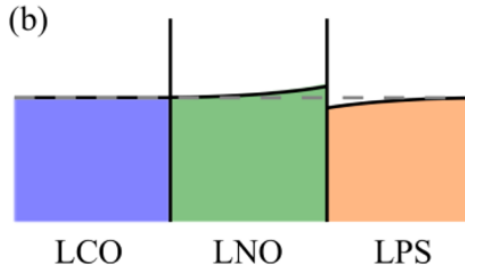

Figure 3. Schematic illustrations of the interfacial Li concentration. The equilibrium concentrations expected by the conventional model and indicated by the present calculations for the LCO/LPS interface. Reprinted with permission from ref. ${ }^{47}$. Copyright (2020) American Chemical Society.

Kitaura et al. reported the same with LCO cathode using microscopy technique, STEM (scanning transmission electron microscopy) where they identified an additional layer that develops spontaneously once LCO is in contact with LPS solid electrolyte ${ }^{48}$. Based on their analyses, this determine the composition of this additional layer which is composed of phosphorous and sulfur but also of Co indicating the decomposition of the electroactive material. These results are in agreement with the one reported by Auvergniot et al, where oxygen was formed in the cell with the decomposition of LCO. This elemental cross diffusion of cobalt can be explained by the strong difference in Li chemical potential between oxides and sulphides, making the lithium oxygen bonds stronger than the lithium sulfur ones, generating an interface called "space charge layer" (Figure 3a). ${ }^{47}$ DFT + U calculations from Haruyama et al. ${ }^{47}$ reveals why it is important then to have a buffer layer between the cathode material and the sulphide-based solid electrolyte. In their work presented in Figure $\mathbf{3 b}, \mathrm{LiNbO}_{3}(\mathrm{LNbO})$ is playing this role. As LNO is an insulating layer, the Li redistribution at the interface, when the coated-active material is in contact with the solid electrolyte, is less important than in the case of LCO directly in contact with LPS material reducing then the decomposition of LCO. Based on this approach several coating strategies were employed in the literature to buffer the decomposition of LCO cathode material. Ohta et al. spray coated LCO cathode materials with nanometres layer of $\mathrm{Li}_{4} \mathrm{Ti}_{5} \mathrm{O}_{12}$ (LTO) or $\mathrm{LiNbO}_{3}$ and using LGPS as a solid electrolyte for electrochemical test 49,50 . In both cases, they noticed the decrease of the interfacial resistance leading to enhance the rate capability and the electrochemical performance of coatedLCO particles. They found out that the better ionic conductivity of $\mathrm{LiNbO}_{3}$ compared to LTO improved even more the electrochemical performance since the interfacial resistance is lower with LNbO. Zhang et al. decided to push further the investigation on coated-LCO/LGPS using several post-mortem techniques $^{51}$. First of all, they demonstrated that LCO is suffering from mechanical instability along prolongated cycling since several fractures and gliding of the particle layers were observed by microscopic techniques. This fracture phenomenon (better described in the next section) leads to particles disconnection (Figure $\mathbf{4}$ model II) and capacity fades since that contrary to liquid electrolyte the "new fresh" surface cannot be wetted properly by the solid electrolyte. Additionally, this fresh surface is not coated and thus LCO starts to

decompose again as explained earlier in this subchapter. Even if the coating is preventing the Co to diffuse at the cathode/SE interface (Figure 4 model I), it was found that after 100 cycles, Co is present in the coating layer indicating that the coating is only buffering the LCO decomposition but not fully preventing it. As for the electrolyte, it decomposed in a similar manner as the one described by Auvergniot et al. ${ }^{44}$, with the appearance of elemental sulfur and $\mathrm{Li}_{2} \mathrm{P}_{2} \mathrm{~S}_{6}$ generating a $\mathrm{Li}$ depletion layer (Figure 4 model III) on the SE. Other materials were tested to improve the LCO performance and interfacial stability. The coating made from $\mathrm{Li}_{2} \mathrm{O}, \mathrm{Si}, \mathrm{SiO}_{2} / \mathrm{Li}_{2} \mathrm{SiO}_{3}, \mathrm{LiTaO}_{3}, \mathrm{LiAlO}_{2}$ and more recently from sulphide like $\mathrm{COS}$ and $\mathrm{NiS}$ demonstrated enhanced electrochemical performance with a lower interfacial resistance and less decomposition products ${ }^{29}, 43,52-55$. Sulphide materials used as coating layer seem to be a nice alternative to ensure chemical stability with a sulfur-based electrolyte. Very recently, Culver et al. published a review dedicated to the coating of cathode materials for LPS-based cell. We encourage the reader to refer to this work to learn more about the coating techniques for solid state batteries. ${ }^{56}$ In a similar basis, Mingjie et al, published a review about the interface engineering of solid state batteries. ${ }^{57}$

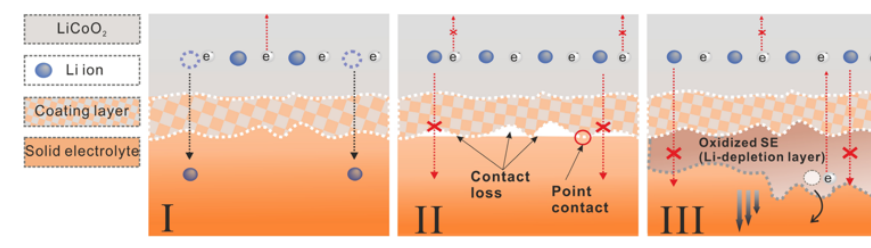

Figure 4. Schematic description of three possible situations occurring in a model SSB with $\mathrm{LiCoO}_{2}$ as the active material and LGPS as the SE. (I) The ideal case: intimate contact between the $\mathrm{SE}$ and $\mathrm{c}-\mathrm{LiCoO}_{2}$, and no mutual reaction or decomposition of the SE. (II) Contact loss due to volume changes or failures during preparation. (III) Decomposition of the SE at high voltages, forming a Li+-depletion layer, thereby inhibiting $\mathrm{Li}^{+}$mobility. Reprinted with permission from ref. ${ }^{51}$. Copyright (2020) American Chemical Society.

Looking now at LMO cathode, Auvergniot et al. ${ }^{44}$ found similar decomposition products as the one reported for LCO but already they noticed the spontaneous decomposition of LMO in contact with LPSCl since the XPS spectrum of the pristine electrode reveals the presence of lithium polysulfides (Figure 5). As mentioned already, this phenomenon is linked to the space charge layer where $\mathrm{Li}$ ions are spontaneously migrating at the composite/electrolyte interface, decomposing the positive electrode. Surprisingly, the mechanical etching, after cycling, reveals that only the upper surface of the composite electrode was covered by decomposition products letting the core of the electrode untouched. This result most probably indicates that a part of the electrode was electrochemically inactive missing electronic percolation and/or the interfacial resistance was too high to ensure a proper Li pathway. The latter might be also related to the fact that already spontaneous reaction occurred once the pristine got in contact with LPSCl electrolyte. Similarly to $\mathrm{LCO}$, several coating procedure were investigated to improve the electrochemical performance of $\mathrm{LMO}^{58} \mathrm{LiNbO}_{3}$ coating helped to reduce the interfacial resistance enhancing the electrochemical performance of the cathode material. 


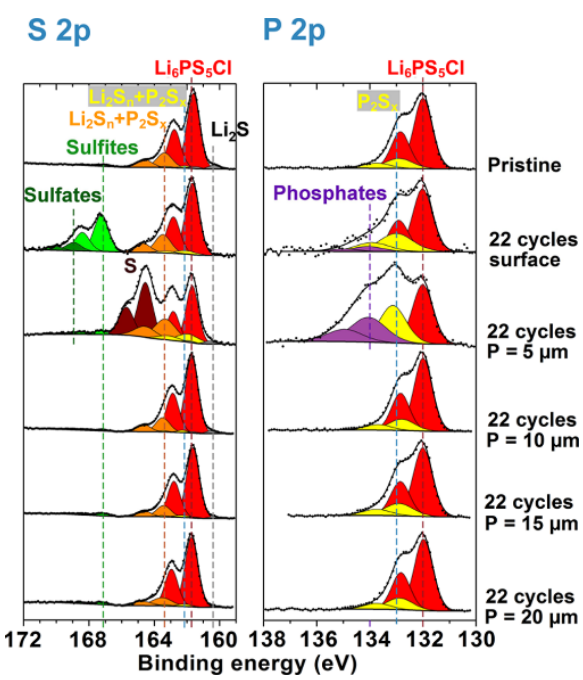

Figure 5. S2p and P2p XPS spectra of the composite LMO electrode of $\mathrm{LMO} / \mathrm{Li}_{6} \mathrm{PS}_{5} \mathrm{Cl} / \mathrm{Li}-\mathrm{In}$ half-cells: before cycling (pristine), after 22 cycles, and after 22 cycles with increasing etching depths of the electrode from 5 to $20 \mu \mathrm{m}$. Reprinted with the permission from ref. ${ }^{44}$. Copyright (2020) American Chemical Society.

Continuing their investigation, Auvergniot et al. investigated NCM111, except that here, the cell was able to run 300 cycles in a rather stable way delivering 60-70 mAh/g. Contrary to LMO, the interface between NCM111 and LPSCl seems rather stable with only a small amount of polysulfides detected after 1 cycle. However, as noticed by the authors, the decomposition products seem to be reversible during the first cycles as the amount of polysulfides detected by XPS is not the same between the charge and the discharge. After 300 cycles, the conclusions are the same as the one observed for LCO, except that during mechanical etching, no difference was found between the surface and the bulk of the composite electrode, indicating a more homogeneous reaction. The better cyclability of NCM111 is then attributed to a more homogeneous reaction through the electrode thickness (better electronic percolation) as well as the partial electrochemical reversibility of the decomposition products 59 , as already observed in the literature for LGPS ${ }^{41}$ and other solid electrolytes. Several studies were also carried out in the literature to understand the degradation mechanisms of NCM family materials. Koever et al. investigated the reaction mechanisms of NCM811 and LPS solid electrolyte using electrochemical impedance spectroscopy (EIS) and XPS measurements ${ }^{60}$. As reported before, the decomposition reaction mechanisms are mostly coming from the oxidation of the solid electrolyte occurring during the first charge (chemical) being also dependent of the cut-off voltage ${ }^{61}$ and of the particles disconnection occurring during cycling due to the contraction (mechanical stability) of the particles during charging.

Jung et al. performed an in-depth investigation of the reaction mechanisms of $\mathrm{NCM}$ and coated-NCM $\left(\mathrm{LiNbO}_{3}\right)$ in solid state batteries ${ }^{62}$. They found out that the bare NCM is decomposing already in contact with the solid electrolyte LPSCl without any current flowing in the cell. The EIS measurement reveals that the grain boundaries resistance is the one evolving the most with time, especially for the bare-NCM revealing a chemical decomposition that might lead to a physical one. Indeed, the investigation made by in situ SEM on the same sample reveals the presence of several cracks even without electrochemical activity. Regarding the decomposition products, they found out the classical ones such as sulfur, polysulfides and others but additionally they also noticed the presence of sulphide byproducts like $\mathrm{NiS}, \mathrm{CoS}$ and $\mathrm{MnS}$ indicating the decomposition of the NCM particles with the leaching of the transition metals. Choi et al. investigated NCM622 electrode material coupled to L7PS solid electrolyte by mean of tomographical analysis ${ }^{63}$. Thanks to this technique coupling laser ablation and mass spectrometry, they could determine the Li content and the transition metal content before and after cycling as well as in the pristine material. Transition metal leaching was noticed like in conventional Li-ion batteries especially for Mn element ${ }^{64,} 65$; for the Li ion, the demonstrated that the Li loss is caused by interfacial mechanisms. Young Kim et al. investigated the impact of hybrid coating (composed of two materials $\mathrm{Li}_{2} \mathrm{CO}_{3}$ and $\mathrm{LiNbO}_{3}$ ) on the cycling performance of NCM622 cycled with LPS solid electrolyte ${ }^{66}$. The hybrid coating was investigated using several characterization techniques including EIS, XPS, SEM, $X R D$ and differential electrochemical mass spectrometry (DEMS) and compared to $\mathrm{Li}_{2} \mathrm{CO}_{3}$-coated NCM material and bare $\mathrm{NCM}$. The hybrid coating outperformed the pristine material and the carbonated-NCM material. This result can be explained by the synergetic effect of $\mathrm{Li}_{2} \mathrm{CO}_{3}$ and $\mathrm{LiNbO}_{3}$ coating reducing the impedance of the system compared to the pristine uncoated NCM622. The XPS analysis reveals a difference not in the chemical composition of the surface layer but more on the extent of the decomposition being higher for bare NCM particles. Finally, the DEMS measurement explained the difference between the hybrid coating and the one composed of only carbonate. The carbonated coating is decomposing along cycling releasing $\mathrm{O}_{2}$ gases which reacts directly with LPS electrolyte generating $\mathrm{SO}_{2}$ gas. The combined $\mathrm{Li}_{2} \mathrm{CO}_{3}-\mathrm{LiNbO}_{3}$ suppressed this reaction pathway improving the long-term cycling stability. Very recently, Neumann et al. ${ }^{67}$ investigated the 3D microstructure simulations based on X-ray tomography measurement of NCM622 cathode material, coupled to LPS, to estimate the amount of effectively used material during cycling. They demonstrated that during the course of lithiation, the electronic conductivity of cathode materials turned to be lower which creates then disconnected area close to the current collector whereas the cathode close to the separator is fully active. Those results are in agreement with the study of Wu et al. 68 The competition between these both processes led to inhomogeneous reaction where the active material is either too much used or not used at all, as can be seen in Figure 6 . 
(a)

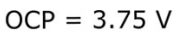

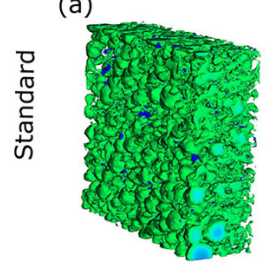

(d)

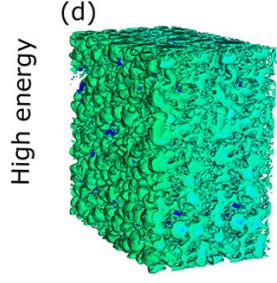

$\mathrm{OCP}=3.3 \mathrm{~V}$

(b)
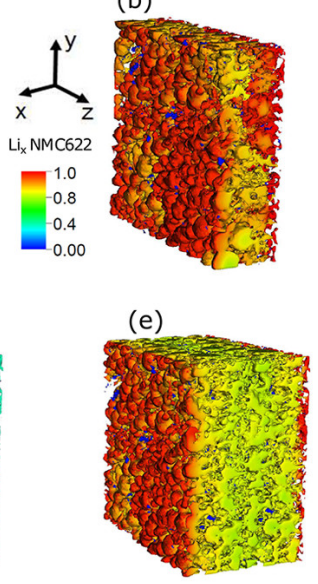

$\mathrm{OCP}=2.8 \mathrm{~V}$

(c)

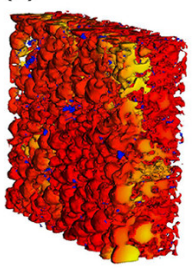

(f)

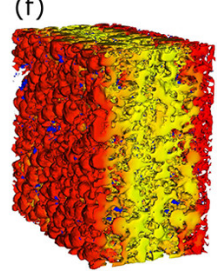

Figure 6. $(a-c)$ Lithium distribution in the active material of the standard composite cathode $(40 \mu \mathrm{m})$ at cell voltages of $3.75,3.3$, and $2.8 \mathrm{~V}$ during a $0.1 \mathrm{C}$ discharge. (df) Concentration distributions in the high-energy cathode $(80 \mu \mathrm{m})$ under the same conditions. Reprinted from ref. ${ }^{67}$. Copyright (2020) American Chemical Society.

Recently, Li et al. ${ }^{69}$, investigated the cathodic surface reaction of Ni-rich cathode materials (NCM811) in contact with LGPS by means of TEM coupled to EELS and operando X-ray absorption near-edge spectroscopy (XANES). They demonstrated the strong reaction between NCM811 and LGPS leading to the decomposition of LGPS into $\mathrm{Li}_{2} \mathrm{~S}$, the diffusion of sulfur into NCM layer pushing also the transition to rock salt structure and a $\mathrm{Li}$ depletion generating a space charge layer as already reported in the literature ${ }^{47}$. An ALD deposition of $\mathrm{LiNbO}_{3}(5 \mathrm{~nm}$ optimal even if authors thickness were also tested) as the surface of NCM811, was found to buffer or even suppress all precited issues leading to a stabilization of the electrochemical performance.

Based on the aforementioned results, the electrode engineering is of utmost importance to control better the decomposition of the electrolyte and the chemical affinity between the electrode components. Several groups investigated the impact of the electrode engineering on the electrochemical performance of NCM materials. Zhang et al. investigated the impact of the electrode engineering on the electrochemical performance of coated-NCM811 and LPSCI solid electrolyte ${ }^{70}$. A slurry-based method was used to enhance the electrochemical performance using a binder (ethyl cellulose) dispersed in ethanol with carbon-black. It was shown that the binder (only $1 \%$ ) was highly beneficial to improve the interfacial contact as well as the mechanical integrity of the electrode (less cracks during cycling). Sakuda et al. determined the impact of the NCM111 particles size coupled to the SE particles ${ }^{71}$. They demonstrated that the homogeneity of the composite cathode electrode materials is better when small SE particles are used. Additionally, at fast cycling rate the combination of small NCM particles coupled to small SE particles led to better electrochemical performance and reversibility. Strauss et al. pursued this investigation by looking at the impact of the secondary particle size of uncoated-

NCM622 in LPS electrolyte ${ }^{72}$. Owing to the good wettability of the electrode/electrolyte in conventional battery, the impact of the particle size is quite often neglected but, in this paper, they demonstrated that this impact is quite severe in the electrochemical performance of solid-state batteries. At first glance, the limited specific capacity obtained from large particle was thought to be kinetically dependent, but even with very low cycling rate, the large particles do not deliver the expected capacity. Thus, some particles are electronically disconnected from the solid electrolyte leading to dead materials in the composite electrode. Additionally, the authors demonstrated that the large particles are virtually less connected to the electron network (less contact point) which also contribute to their poor cyclability.

Through this first part, we demonstrated the difficult challenge to obtain reliable electrochemical performance in LPS-based solid electrolyte systems that tends to decompose during oxidation. Combination of coating of the active materials as well as buffer layer at the EEI with a proper electrode engineering leads to improve the cycling stability and the long-term performance. In the next chapter, we will be looking at the behaviour of the solid electrolyte during reduction.

\section{Negative electrode interface (reduction of the solid electrolyte)}

$\mathrm{Xu}$ et al. investigated the reaction mechanisms of LTO vs. InLi using LPS by ex situ XPS. ${ }^{73,74}$ They found that the LPS is reacting with $\mathrm{Li}$ metal and start to decompose in elemental sulfur, $\mathrm{Li}_{2} \mathrm{~S}$ and polysulfides in agreement with the theoretical calculation and literature. ${ }^{36,75}$ During cycling this negative electrode interface evolves and the decomposition products are made of sulfur but also of phosphorus with the appearance of phosphates and InP. Surprisingly during cycling, the interface of LTO vs. SE was found to be stable, but the reversibility of LTO was questioned since some traces of $\mathrm{Ti}^{3+}$ remain visible after couple of cycles. This interface stability allowed cycling LTO vs InLi during 100 cycles at $25^{\circ} \mathrm{C}$ with a specific capacity of ca. $125 \mathrm{mAh} / \mathrm{g}$ and a Coulombic efficiency close to $99 \%$.

\section{Li metal interface (reduction of the solid electrolyte)}

Unfortunately, sulphide-based solid electrolyte, with their very narrow electrochemical stability window, are subjected to strong reduction at low potential especially when they are in contact with Li metal. ${ }^{14}$ Two issues arise when sulphide-based solid electrolytes are in contact with Li metal i) their enhanced decomposition and, ii) the development of Li metal dendrite hindering the cycling performance. For both, the most common strategy is to replace Li metal by an In-Li alloy ${ }^{76}$ because i) the process of dendrites formation is reduced, ii) the electrolyte decomposition is less pronounced with In-Li alloy and ii) the electrochemical performance of positive and negative electrode materials can be assessed properly. Unfortunately, the In-Li alloy is only a strategy to be used in academic research as the potential of Li-In is $620 \mathrm{mV}$ higher than the one of Li metal 
resulting in very poor energy density. In this sub-chapter we will review the researches dealing with the investigation of the interface between SE and Li metal as well as the strategy to tackle this decomposition.

Camacho-Forero and Balbuena investigated the stability of several sulphide-based solid electrolytes in contact with $\mathrm{Li}$ metal using DFT calculation and $a b$ initio molecular dynamics $(A I M D)^{77}$. They demonstrated that there is a diffusion of $\mathrm{Li}$ ion through the SE and vice versa and that the rate of the diffusion is dependent of the crystal orientation and of the chemistry of the solid electrolyte as can be seen in Figure 7. $\mathrm{Li}_{2} \mathrm{P}_{2} \mathrm{~S}_{6}$ is then the less stable structure especially when the crystal is oriented in (100), and $\mathrm{Li}_{7} \mathrm{P}_{3} \mathrm{~S}_{11}$ seems to be the more stable one if oriented in (100) direction. Surprisingly, $\mathrm{Li}_{3} \mathrm{PS}_{4}$ is found to be more stable than LGPS which is in general contradiction with the literature. Regarding the decomposition at the Li metal surface, most of the issues arise from the $\mathrm{PS}_{4}{ }^{3-}$ groups that decomposed by breaking P-S bound. However, in the case of $\mathrm{Li}_{7} \mathrm{P}_{3} \mathrm{~S}_{11}$, the decomposition proceeds through $\mathrm{P}_{2} \mathrm{~S}_{7}$ anion reducing to $\mathrm{PS}_{3}$ and $\mathrm{PS}_{4}$ which can further decompose as aforementioned but to a less extend. Finally, the $\mathrm{Li}_{2} \mathrm{P}_{2} \mathrm{~S}_{6}$ phase is more exotic and decomposes in side-products like $\mathrm{P}_{3} \mathrm{~S}$ further decomposing leading to LiP and related family members. The further reduction of those side-products leads to the formation of $\mathrm{Li}_{3} \mathrm{P}$, $\mathrm{Li}_{2} \mathrm{~S}, \mathrm{~S}, \mathrm{P}$ and in the case of LGPS, $\mathrm{Li}_{15} \mathrm{Ge}_{4}$. This theoretical approach shows the severe and drastic decomposition of the solid electrolyte once in direct contact with $\mathrm{Li}$ metal. The addition of a thin layer of $\mathrm{Li}_{2} \mathrm{~S}$ thin film, in the theoretical model, at the surface of Li metal buffers the decomposition of the solid electrolyte leading to better cycling stability theoretically.
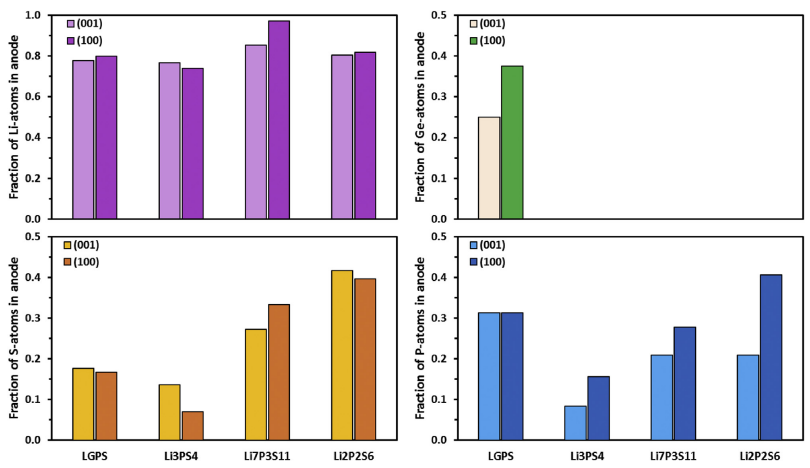

Figure 7. Anode atomic fractions after 20 ps of AIMD simulation. As anode, we referred the area of the cell that was comprised by the 9-layer Li-slab prior SSE/Li geometry optimization. Therefore, the fraction of Li corresponds to the Li-species that remains at the anode area after $20 \mathrm{ps}$, whereas the other fractions ( $\mathrm{S}, \mathrm{Ge}$, and P) are the amount of such species that moved to the anode side during the relaxation/dynamic evolution. Reprinted with the permission from ref. ${ }^{77}$. Copyright (2020) with permission from Elsevier.

Wenzel et al. did a deep investigation upon the instability of LGPS solid electrolyte once in contact with Li metal78. Coupling in situ XPS measurement and EIS results they demonstrated that LGPS is more unstable than L7PS since the solid electrolyte interphase (SEI) thickness is 10 times higher on LGPS compared to L7PS 79 . By cooling down the sample to $-90^{\circ} \mathrm{C}$ they could avoid sulfur loss and slow down the reaction kinetics, but this is highly detrimental to the ionic conductivity of the SE. By depositing Li metal (sputtering) onto the LGPS sample, several side reaction products were found at the interface Li metal/SE, mostly $\mathrm{Li}_{2} \mathrm{~S}$, $\mathrm{Li}_{3} \mathrm{P}$ and $\mathrm{Ge}^{\mathrm{O}}$. For the latter one, however, there is a debate in the literature, if yes or no, $\mathrm{Ge}^{0}$ can be stabilized. Indeed, theoretical calculation demonstrated that $\mathrm{Li}_{15} \mathrm{Ge}_{4}$, should be formed because it is thermodynamically more stable, but no experimental proof evidenced it, so the debate it to date this open. Unfortunately, $\mathrm{Ge}^{0}$ has another bad influence on the SEI formation leading to increase locally the electronic conductivity which has a side effect since it increases the average transport coefficient of Li metal leading to faster SEI growth (Figure 8).

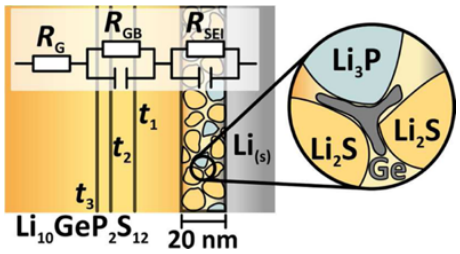

Figure 8. Schematic of the interphase formation at the Li/LGPS interface. The decomposition leads to different binary compounds with poor transport properties, such as $\mathrm{Li}_{3} \mathrm{P}, \mathrm{Li}_{2} \mathrm{~S}$, and $\mathrm{Ge}$ (or $\mathrm{Li}_{15} \mathrm{Ge}_{4}$ ), leading to an increasing interfacial impedance with the time. Reprinted with permission from ref. ${ }^{78}$. Copyright (2020) American Chemical Society.

Wenzel et al. pursued their investigation of stability at the Li metal interface with argyrodite solid electrolyte $\mathrm{Li}_{6} \mathrm{PS}_{5} \mathrm{X}(\mathrm{X}=\mathrm{Cl}$, $\mathrm{Br}, \mathrm{I})^{80}$. To this point, they used in situ XPS technique where the $\mathrm{Li}$ is directly deposited at the surface of the solid electrolyte. As expected, they identified the formation of $\mathrm{Li}_{2} \mathrm{~S}, \mathrm{Li}_{3} \mathrm{P}, \mathrm{LiCl}$ (or $\mathrm{LiBr}$ or Lil) and Li metal, which growing rates increase with time at the beginning of the deposition indicating that the decomposition products are form rapidly but do not grow significantly with time. Additionally, they established a model based on time-resolved impedance spectra to determine the interphase growth rate ${ }^{78,79}$. Due to the strong reaction between the Li metal and the solid electrolyte, the interfacial resistance is found to be growing with time. The resistance and grow rate are similar for the $\mathrm{Cl}$ and $\mathrm{Br}$ based solid electrolyte, but the one containing iodine is higher indicating another decomposition process leading to more resistive interface. Based on this study, Li7PS seems to be the most promising solid electrolyte with a compromise between a good ionic conductivity and a reasonable interfacial degradation.

To tackle the problem of the solid electrolyte decomposition once in contact with $\mathrm{Li}$ metal, several groups worked on strategies mostly related to coating approach or architectural modification ${ }^{29}$. Xu et al. reported that Lil or LiF used as coating layer at the surface of the Li metal helps to prevent the reduction of the solid electrolyte ${ }^{81}$. This first step was realised under Ar atmosphere where iodine and fluorine precursors are vaporized on Li metal surface. To make their buffer layer viable and improve the contact between the solid electrolyte and the Li metal, they infiltrated the solid electrolyte surface either with a layer of I (for Lil coating) or with methoxyperfluorobutane (so called HPE for LiF coating). They obtained an optimal interface 
where the solid electrolyte is not in direct contact with Li metal avoiding then the reduction of the SE as certified by EIS. Indeed, using symmetric cell, they noticed that when Li metal is in contact with the solid electrolyte, degradation products such as $\mathrm{Li}_{2} \mathrm{~S}$ and $\mathrm{Li}_{3} \mathrm{P}$ are generated increasing the interfacial resistance whereas when the cell using the Lil/LiF coating are used the interfacial resistance is three times lower. Owing to this concept, they reported impressive electrochemical performance of $\mathrm{LiCoO}_{2}-\mathrm{LiNbO}_{3}$ coated /L7PS/Li metal cell cycled over 100 cycles at room temperature delivering ca.110 mAh/g at slow rate with reasonable electrode loading. Chen et al., by using first principle calculation, decided to investigate the impact of $\mathrm{Li}_{2} \mathrm{~S}$ as a buffer layer between Li metal and LPSCl to enhance the interfacial stability ${ }^{82}$. The detailed investigation reveals that the presence of $\mathrm{Li}_{2} \mathrm{~S}$ buffer the transition from LPSCI to $\mathrm{PS}_{4}$ avoiding the enhanced decomposition of the $\mathrm{SE}$ as well as prohibiting the decomposition into elemental $\mathrm{S}$ and $\mathrm{Cl}$. In a similar approach, Kizilaslan and Ahbulut used $\mathrm{Li}_{3} \mathrm{~N}$ coating on the top of Li metal to prevent the decomposition of L7PS solid electrolyte ${ }^{83}$ using sulfur/graphene oxide as positive electrode materials. The nitride materials were quite often discussed in the literature as nice alternative enabling Li metal electrode in $\mathrm{Li}$-ion batteries ${ }^{84}$. Along cycling, their full cells with either $\mathrm{Li}$ metal or $\mathrm{Li}_{3} \mathrm{~N}$ counter electrode, demonstrated that the cell built-up with $\mathrm{Li}_{3} \mathrm{~N}$ is not suffering any polarisation problem but it is performing less good than the Li metal one during the first 50 cycles showing an improvement under long-term cycling. More recently, Zhao et al. ${ }^{85}$ investigated the impact of fluorinating an argyrodite solid electrolyte to improve the interfacial resistance between $\mathrm{Li}$ metal and SE and avoid the dendrites formation. Based on a solid-state synthesis route, they obtained an argyrodite sample where $30 \%$ of the $\mathrm{Cl}$ was replaced by F. Owing to this approach, they demonstrated that the densification of the SE was easier with F-based solid electrolyte which leads to reduce the number of dendrites. A deep surface/interface analysis revealed that, as the fluorine is diffusing in the Li metal once in contact with SE, it is generating a stable interface made of LiF, a so-called activation process that allowed Li plating/stripping at very high current density of $6.37 \mathrm{~mA} . \mathrm{cm}^{-2}$. This solid electrolyte was tested in full cell configuration with Li metal counter electrode, in contact with FLPSCl, then the solid electrolyte used was LPSCI and finally the composite electrode was made of coated LCO with LNO and LPSCl solid electrolyte. Owing to the good interfacial contact at the positive and at the negative electrode, the cell delivered a specific capacity of $122 \mathrm{mAh} / \mathrm{g}$ during the first cycle with a CE of $89 \%$. After 50 cycles, the capacity retention is till more than $95 \%$ a result never reported so far.

Sang et al. investigated the role of interlayers between the $\mathrm{Li}$ metal and the SE in decreasing the overall interfacial resistance and dendrites growth ${ }^{86}$. Depending on the chemical nature of the layer, $\mathrm{Li}_{2} \mathrm{~S}$ will be generated at the interface or not. Indeed, with $\mathrm{Si}$ layer, $\mathrm{Li}_{2} \mathrm{~S}$ develops at the interface whereas with $\mathrm{Li}-\mathrm{Al}$ $\mathrm{O}, \mathrm{Li}_{2} \mathrm{~S}$ is not detected. In both cases, the interfacial resistance is increasing because of the presence of the interlayers resulting in kinetics hindrance. Further investigations lead to link the decomposition product to the electrochemical potential applied (in reduction or oxidation). In the case of gold ( $\mathrm{Au}$ ), during reduction, an Li-Au alloy is created that would then decompose the LPS electrolyte into $\mathrm{Li}_{4} \mathrm{P}_{2} \mathrm{~S}_{7}$. During oxidation, $\mathrm{Li}_{2} \mathrm{P}_{2} \mathrm{~S}_{6}$ is generated at the interface but, if the potential is held a certain period of time, the $\mathrm{Li}-\mathrm{Au}$ starts to delithiate stabilising back $\mathrm{Li}_{3} \mathrm{PS}_{4}$. In the case of $\mathrm{Si}$, the reduction of the potential leads to the formation of $\mathrm{Li}-\mathrm{Si}$ alloy generating a decomposition product like $\mathrm{Li}_{4} \mathrm{P}_{2} \mathrm{~S}_{6}$. If now, the sample goes in oxidation, $\mathrm{Li}-\mathrm{Si}$ will delithiated first leading to stabilize again $\mathrm{Li}_{3} \mathrm{PS}_{4}$ phase.

Through this interfacial part, we demonstrated that in oxidation as well as in reduction, the chemical stability of the solid electrolyte is difficult to tackle. We also demonstrated that the chemical instability can lead to a physical one, i.e. the mechanical instability at the interface but also during cycling, due to the electrode breathing.

\section{Mechanical issues}

To date, there are only few reports about the mechanical stability of the solid-state batteries using sulphide-based solid electrolyte or ceramics based-ones ${ }^{87,88}$, but the report reveals important fracture occurring during cycling leading to the rapid cell failure. As for the interfacial issues, fractures, stresses and strains can happen either in the composite electrode, or in the full cell (including the separator which is here the sulphidebased solid electrolyte). Zhang et al. investigated the mechanical stability of a LCO/LGPS/InLi $x_{x}$ cell using X-ray microscopic tomography and dilatometry to follow the impact of the applied pressure on the electrochemical performance ${ }^{89}$. As known during cycling, LCO is experiencing a $10 \%$ volume change which leads to the local densification of the electrode as observed by the evolution of the porosity in the $\mathrm{X}$-ray tomogram being less pronounced at the end of the delithiation compared to the pristine. The volume change leads to a bending of the stack which as a consequence fractures the edge of the pellet already after one cycle indicating that the $\mathrm{ECl}$ interfaces is unstable even with small volume changes. Indirectly, Whiteley et al. investigated the impact of the pressure during electrochemical cycling of nano Sn particles in all solid state batteries ${ }^{90}$. They suggested that the high pressure applied in the electrochemical cell is maintaining the contact between the SE and the Sn particles during cycling; however, with a minimal pressure, contact is lost due to the large volume expansion experience with Sn particles. Upon long-term cycling, the electrochemical performance of the sample with negligible pressure is fading faster than the one with high pressure due to the isolation of $\mathrm{Sn}$ particles from the electronic/ionic network (caused by the large volume expansion of Sn particles). However, those "lost" particles turned to be active at higher lithiation stage due to the large volume expansion of the overall electrode, establishing again the contact with the disconnected particle. Wu et al., investigated a similar system based on micro Sn particles and assess the mechanical stability of this electrode material coupled to LPS solid electrolyte using operando X-ray 
microscopic tomography ${ }^{68}$. During lithiation, they noticed the large volume changes occurring in Sn particle and a core-shell lithiation process as already described in the literature using similar materials ${ }^{91}$. The volume change of the $\mathrm{Sn}$ particles is accompanied by the appearance of large fractures in the solid electrolyte surrounding the particles and propagating in the composite electrode (Figure 9). The fractures appear to be anisotropic, i.e. horizontally oriented (along the $X$ and $Y$ axis) and almost none of the $Z$ one. It is clear based on these images, that the Li pathway will be drastically hindered during cycling. Additionally, Li gradient was noticed along the electrode thickness. Surprisingly during delithiation, most of the fractures disappear (or at least not detectable with the resolution employed) and the composite electrode is going back to its initial volume thanks to the small elastic behaviour of LPS. Unfortunately, another problem occurred at the particle/solid electrolyte interface since a shell void was detected. According to the authors, this void is created by the large volume change experienced by $\mathrm{Sn}$ that changed the particle morphology leading to small voids that cannot be filled properly. As a consequence, the particles tend to be disconnected from the conductive network and leads to battery failure. Kato et al. obtained a similar behaviour by employing Si particles as active materials ${ }^{92}$. However, their approach was different since they investigate the impact of lithium halide additive into the solid electrolyte. Their goal was then to decrease the Young moduli factor of the solid electrolyte to improve its mechanical stability. They found out that the addition of $30 \%$ of Lil to a mixture of LPS reduced the Young modulus and thus enhanced the electrochemical performance of the cell, leading them to conclude that the mechanical stability of the cell was improved.

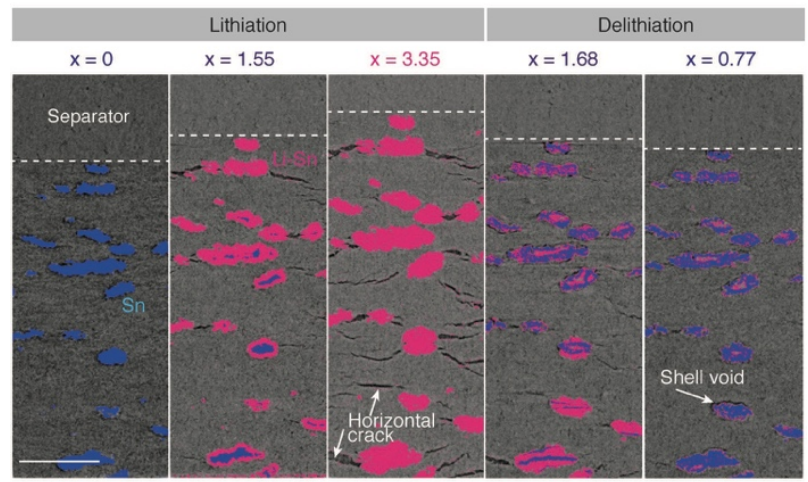

Figure 9. Visualization of WE. a) Cross-sectional image of WE at various SOCs. The Sn and Li-Sn phases are coloured in blue and pink, respectively. The dashed line represents the border between the WE and separator. Scale bar $=100 \mu \mathrm{m}$. The thickness of the electrode increased during lithiation and decreased during delithiation. The horizontal cracks propagated with lithiation and disappeared during delithiation. The shell void appeared at fully delithiated state. Reprinted with the permission from ref. ${ }^{68}$. Copyright permission (2019) from John Wiley and Sons.

As mentioned in the work of $\mathrm{Xu}$ et al. ${ }^{68}$, the ionic transport is hindered in the composite electrode once the tortuosity increased caused by crack propagation. Hlushkou et al. investigated the impact of voids on the ionic transport in a composite cathode for all solid state batteries ${ }^{93}$. They conducted their investigation about tortuosity factor on LCO/LPS-Lil composite electrode following two strategies, the impedance spectroscopy and 3D image reconstruction from focused ion-beam (FIB/SEM). From the EIS measurement and using symmetric Li/LPSI/Li cells, they extracted a tortuosity factor $(\tau=1.6)$ that they compared to the one obtained from the 3D image reconstruction $(\tau=1.7)$. The value was found similar but highly dependent of the number of voids present in the cathode composite electrode. By adding a resin filler to the electrode fabrication, they determine that the voids correspond to $12 \%$ of dead volume, and that if we could replace this dead volume by solid electrolyte, the tortuosity factor will be drastically reduce to a more reasonable value of $(\tau=1.27)$ indicating that the engineering of the electrode is a crucial step to ensure proper $\mathrm{Li}$ ion transport along the electrode. These results are also in agreement with the work of Wu et al. ${ }^{68}$, who applied stronger pressure on the cell stack after one cycle, to close the shell voids observed for Sn particles in operando X-ray tomography. With this approach they reduce the voids present in the electrode and manage to recover some lost charges. Koerver et al. ${ }^{60}$ linked the capacity faded of LPS/NCM811 cell to the mechanical expansion/constriction of the NCM particles. They demonstrated by using post-mortem SEM experiment that there are spherical gaps around the NCM particles after cycling which is caused by the volume expansion/shrinkage of the particles. The mechanical stress caused by the volume changes coupled to the enhanced decomposition at high voltage investigated by means of EIS, the authors elucidated the contact loss of the particles within the electrolyte network and demonstrated that this phenomenon is amplified after each successive cycle.

Most of the pre-cited reports are dedicated to the investigation of the mechanical issues occurring in the composite electrode ( $\mathrm{ECl}$ as described in Figure 1) and only the work of Wu et al.68 described also the impact of extensive volume change in the solid electrolyte as such. Koerver et al. did a full investigation of strain/stress propagation in a half and full cell configuration, to investigate the impact of volume change in a global approach in a solid state batteries using LGPS as a SE ${ }^{94}$. They demonstrated that several factors need to be considered when it comes to stress/strain, i.e. the volume change of the active materials, the porosity of the composite electrode, the softness of the solid electrolyte as well as its plasticity. Based on their results, it seems possible to compensate the mechanical stress i) by using a zero-strain electrode material, but in this case, the specific charge obtained from the electroactive materials are generally poor, ii) by compensating the large volume expansion of one active material by coupling it to a large shrinkage electrode material as described in the example given in the study, i.e. LCO coupled to NCM811. In this regard, Fitzhugh et al. described nicely the impact of the pressure and the mechanical constriction on the sulphide-based solid electrolyte itself during cell assembly and during operation ${ }^{95}$. Indeed, during cycling, not only the electrode materials are suffering from breathing processes, the solid electrolyte as well is evolving which leads to additional mechanical stress. According to the authors, the inconsistent stability reports observed in the literature are directly linked to the mechanical constriction of the sulphidebased solid electrolyte which is different as it depends of the 
cell set-up and the applied pressure during cycling and cell assembly. As an example, some reports claimed that LGPS can be stable up to $4 \mathrm{~V}^{8}$ whereas others claimed that the stability windows is not exceeding $2.5 \mathrm{~V}$ upon oxidation ${ }^{96}$. The solid electrolyte nature as well as its synthesis and its protection (by core-shell technique or coating) are one of the key issues to control the mechanical stability and electrochemical stability. $\mathrm{Wu}$ et al. used the aspect of mechanical constriction to developed core-shell LGPS solid electrolyte ${ }^{38}$ leading to drastically enhanced the electrochemical stability windows. In fact, the shell structure serves as a pressure vessel and protect the core of the solid electrolyte. Unfortunately, the engineering of the shell is not straightforward and it has the tendency to have a different microstructure than the core which leads also to a different ionic conductivity, generally lower ${ }^{97}$.

Another system currently under intense investigation, is the Li$\mathrm{S}$ solid state batteries due to the affinity of sulfur as cathode material and as solid electrolyte improving then the interfacial contact $^{98,99}$. Ohno et al., investigated the chemo-mechanical degradation occurring in Li-S solid state batteries ${ }^{100}$. By using two types of composite cathode (one mixed by hand and another one mixed mechanically by ball milling), they demonstrated that the chemical instability is also linked to the mechanical one. Indeed, they found out an antagonist behaviour of Li-S solid-state batteries since to improve the electrochemical performance, electronic conductivity is needed in the composite electrode, but carbon additives are known to enhance the electrolyte decomposition ${ }^{96,101}$. In the hand mixed sample, the contacts are poor between the SE, the carbon additive and the Li-S leading to poor electrochemical performance but high efficiency. The ball milled sample is then having optimal contact between the different component leading to very high capacity but poor efficiency due to the enhanced electrolyte composition. Surprisingly, the electrochemical performance of the hand mixed sample improved during cycling which is due to the volume change of the sulfur cathode electrode which improves the contact by densifying the composite electrode. On the other hand, the ball milled sample is suffering accelerated fading which is caused by i) the presence of conductive additive and ii) the more severe volume change occurring in the sample (because more charges are exchanged) causing mechanical fractures leading to reveal fresh surface enhancing the decomposition. By lowering the cut-off potential of the ball milled sample, the electrochemical performance decreased but tends to be more stable buffering the chemo-mechanical failure.

These mechanical investigations demonstrated several issues to be tackled at the composite level but also in the cell as such due to the impact of mechanical stress on the solid electrolyte integrity. It was demonstrated that not only the optimal contact between the electrode and electrolyte is vital, but also that to ensure long-term cycling two mains strategies can be employed:

- Selection of a cathode and an anode that undergo minimal volume changes during cycling. In this case, only insertion-based materials can be selected leading to a rapid limitation of the electrochemical performance of the solid-state batteries.

- Investigation of hybrid-based electrolyte including a certain percentage of polymer materials allowing a mechanical stability due to an extent Young modulus.

We will describe the latter in the following sub-chapter.

\section{Hybrid solid electrolyte}

As seen previously, the cycling performance of SSBs are both limited by interfacial issues mostly coming from the chemical instability of the solid electrolyte as a function of the voltage (reduction and oxidation) and by a mechanical weakness due to the poor ductility of the solid electrolyte during electrochemical process (breathing)/manufacture ${ }^{102}$. For the latter issue, a strategy was proposed to bring some flexibility/elasticity to the solid electrolyte by mixing it with a Solid Polymer Electrolyte (SPE) ${ }^{103-105}$. This new type of solid-state batteries is commonly referred to Hybrid Solid Electrolyte (HSE) batteries or few times by Composite Polymer Solid Electrolyte (CPSE) batteries ${ }^{106,107 .}$ Adding an inorganic filler into SPE electrolytes was already demonstrated in the literature to decrease the crystallinity of the SPE and thus, improve the ionic conductivity of the composite by increasing the amount of amorphous polymer chains responsible of ions motion ${ }^{108-111}$. The idea of HSE is not entirely new, as it was already investigated in $1982^{112}$, but regain a lot of interest with the development of novel super ionic conductors. ${ }^{113,}, 114$

Solid polymer electrolytes such as PEO (used as a filler in the case of HSE) offer the advantages of i) a good flexibility, ii) a proper wettability, and even for some of them, iii) a good chemical stability at high voltage $\mathrm{e}^{115-118}$, but they suffer very low ionic conductivity requiring high temperature for operation and also from an unstable contact with $\mathrm{Li}$ metal, leading to decomposition products but still without huge consequence on electrochemical performance ${ }^{119-121}$. This latter point is of high importance for the development of better solid electrolyte since we demonstrated in the first part of this paper that the Li metal interface/SE is highly unstable leading to decomposition into $\mathrm{Li}_{2} \mathrm{~S}$ and $\mathrm{Li}_{3} \mathrm{P}$. Consequently, HSE might not only improved the mechanical stability during cycling but also the chemical stability of the electrolyte-electrode interfaces by reducing the amount of decomposition products responsible of the high interfacial resistance. However, high temperature might be needed to compensate the loss of ionic conductivity.

One challenge of making hybrid electrolyte viable, is the dispersion of the SE into the polymer matrix or vice-versa, depending of the weight ratio used. Several preparation routes were presented in the literature, like the "simple" mixture of both components ${ }^{107}$, being easy to process and inexpensive. However, some studies reported the inhomogeneity of this "simple" approach and, designed a layered "sandwich" consisting of a thin polymer film in between the solid electrolyte and the composite electrode or even more complex a "sandwich" design consisting of polymer/SE/polymer 30, 113, 122- 
${ }^{124}$. For the latter design, an additional step implying a sintering step at high temperature was performed to reduce the interfacial resistance between the SE and the polymer. If the manufacture of the polymer embedded in the SE is relatively easy, questions arose about the chemical and electrochemical stability.

\section{Electrochemical performance}

The pioneer work on HSE concept was performed using LATP $\left(\mathrm{Li}_{1.3} \mathrm{Al}_{0.3} \mathrm{Ti}_{1.7}\left(\mathrm{PO}_{4}\right)_{3}\right)$ as $\mathrm{SE}$ coupled to a polymer matrix composed of PVDF - HFP / LiBOB / polyphosphazene. ${ }^{113}$ LATP is known to i) decompose easily once in contact with Li metal causing the reduction of $\mathrm{Ti}$ and, ii) poor mechanical stability along cycling causing enhanced capacity fading. Yu et al. ${ }^{113}$ proposed a protective polymer layer to be deposited between LATP and Li metal to tackle both precited issues. Thanks to microscopy technique (Figure 10), they demonstrated that the SE particles are well embedded in the polymer matrix leading to an intimate contact at the interfaces (very little porosity noticed). In addition, elemental mapping as well as electrochemical impedance spectroscopy reveal no diffusion or segregation between the two phases demonstrating the good chemical stability in the HSE. They tested the electrochemical performance of their hybrid solid electrode using $\mathrm{Li}$ metal counter electrode and a mixture of CNT and $\mathrm{Li}_{3} \mathrm{~V}_{2}\left(\mathrm{PO}_{4}\right)_{3}$ as cathode material at $50^{\circ} \mathrm{C}$ and compared it to a cell cycled with LP30 liquid electrolyte at $25^{\circ} \mathrm{C}$. The results are kind of impressive since the cell was cycled without strong fading for more than 500 cycles at $\mathrm{C} / 5$ (from ca. $125 \mathrm{mAh} / \mathrm{g}$ to $108 \mathrm{mAh} / \mathrm{g}$ ). However, the electrochemical stability windows used for the test was rather small between $3 \mathrm{~V}$ and $4.2 \mathrm{~V}$ vs. $\mathrm{Li}^{+} / \mathrm{Li}$ and with an unknown loading of electroactive material.

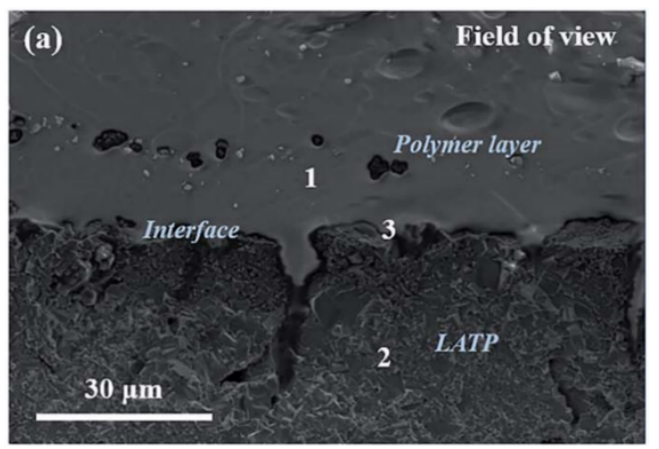

Figure 10. Cross-sectional SEM images of the layered hybrid solid electrolyte: (a) field of view image of the polymer-ceramic interface. Reprinted from ref. ${ }^{113}$ Published by The Royal Society of Chemistry.

Similarly, Chen et al. ${ }^{125}$ investigated another type of HSE based on PEO coupled to LGPS. The working principle was to develop a hybrid electrolyte where a plasticizer succionitrile (SN) is coupled to an inorganic filler (LGPS) and both are embedded in PEO based polymer electrolyte matrix. The role of these fillers is then to increase the amount of amorphous PEO network to enhance the ionic conductivity and ion transport. Prior to perform any measurement, the authors ensure that there is no degradation between the LGPS materials and PEO as the opposite was reported in other studies ${ }^{107,126,127 .}$

They found out that the best compromise for chemical affinity and ionic conductivity is to introduce only $1 \mathrm{wt} . \%$ of LGPS and $10 \mathrm{wt} . \% \mathrm{SN}$ leading to an ionic conductivity 15 times higher than the one of PEO-LiTFSI without filler. The electrochemical stability window of this hybrid electrolyte was found to be from $0 \mathrm{~V}$ up to $5.5 \mathrm{~V}$ vs. $\mathrm{Li}^{+} / \mathrm{Li}$ as demonstrated by $\mathrm{CV}$ test and the authors attributed this impressive behaviour to the addition of LGPS filler into PEO matrix. Electrochemical tests were performed using Li metal as a counter electrode and $\mathrm{LiFePO}_{4}$ as positive electrode material. The measurement was performed at $40^{\circ} \mathrm{C}$ to ensure a better ionic conductivity of the hybrid electrolyte system. As reported, it takes several cycles (so called activation cycled by the authors) to reach a stable cycling stability. The cell LFP/HSE/Li cycled at C/10 rate (Figure 11) demonstrated a capacity retention of $150 \mathrm{mAh} / \mathrm{g}$ after more than 80 cycles. However, as faster rate, the fading is more pronounced since after 80 cycles, the cell reached a capacity of ca. $120 \mathrm{mAh} / \mathrm{g}$. They found out that the duration of the activation process is function of i) the operating temperature ii) the electrolyte ionic conductivity and iii) the applied cycling rate.

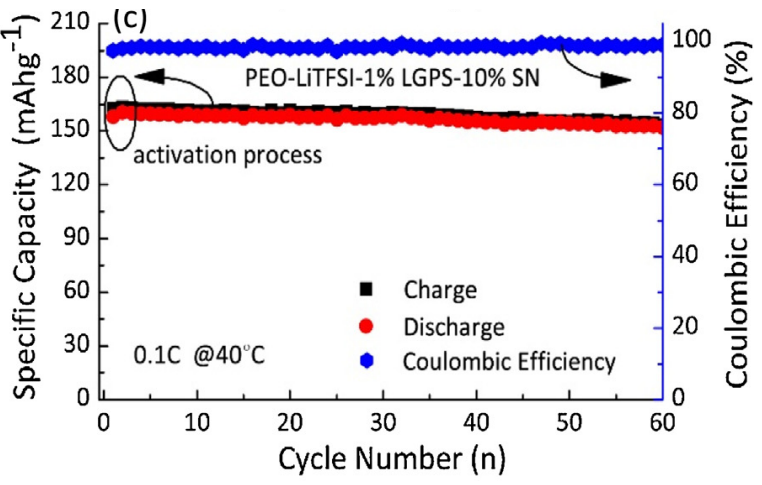

Figure 11. The cycling and rate performance under $40^{\circ} \mathrm{C}$ for all-solid-battery Li/PEOLiTFSI-1\%LGPS-10\%SN/LiFePO ${ }_{4}$ at $0.1 \mathrm{C}$ rate. Reprinted from ref. ${ }^{125}$. Copyright (2020), with permission from Elsevier.

Zhao et al. ${ }^{114}$ reported a similar approach by developing HSE electrolyte based also on PEO(LiTFSI)- coupled to $1 \mathrm{wt} . \%$ of LGPS particle. They demonstrated that the addition of LGPS is beneficial in several aspects i) the electrochemical stability window which is extended from $4.8 \mathrm{~V}$ to $5.7 \mathrm{~V} \mathrm{vs}$. $\mathrm{Li}^{+} / \mathrm{Li}$, ii) the ionic conductivity increases also with $1 \mathrm{wt} \%$ LGPS incorporation, and iii) the interfacial stability at the Li metal electrode is also improved and do not evolve significantly during ageing. Electrochemical tests were conducted with the composite electrolyte in $\mathrm{LiFePO}_{4} / \mathrm{Li}$ cell. This time, the cycling test was performed at $60^{\circ} \mathrm{C}$ and revealed $92.5 \%$ capacity retention after 50 cycles at $0.5 \mathrm{C}$ cycling rate (from $149 \mathrm{mAh} / \mathrm{g}$ to $137 \mathrm{mAh} / \mathrm{g}$ ). We tried to summarize the results obtained in both precited papers, as both reported same electroactive materials and bother are PEO based LGPS HSE, in Table 2, for sake of comparison. 
Table 2. Electrochemical performance obtained from ref. ${ }^{114}$ and ref. ${ }^{125}$

\begin{tabular}{|c|c|c|c|c|}
\hline \multirow[b]{2}{*}{$\begin{array}{c}\text { Cycling } \\
\text { rate }\end{array}$} & \multicolumn{2}{|c|}{$\begin{array}{l}\text { Chen }^{125} \text { / Fist cycle discharge } \\
\text { specific capacity at } 40^{\circ} \mathrm{C} \text { of } \\
\text { LiFePO }_{4} / \text { LGPS-PEO-SN/Li cell }\end{array}$} & \multicolumn{2}{|c|}{$\begin{array}{c}\text { Zhao }{ }^{114} / \text { Fist cycle } \\
\text { discharge specific capacity } \\
\text { at } 60^{\circ} \mathrm{C} \text { of LiFePO } \\
\text { PEO/Li cell }\end{array}$} \\
\hline & $\begin{array}{l}\text { Discharge } \\
\text { capacity } \\
\left(\mathrm{mAh} \cdot \mathrm{g}^{-1}\right)\end{array}$ & $\begin{array}{l}\text { Percentage of } \\
\text { the theoretical } \\
\text { capacity }\end{array}$ & $\begin{array}{c}\text { Discharge } \\
\text { capacity } \\
\left(\mathrm{mAh} \cdot \mathrm{g}^{-1}\right)\end{array}$ & $\begin{array}{l}\text { Percentage } \\
\text { of the } \\
\text { theoretical } \\
\text { capacity }\end{array}$ \\
\hline $0.1 \mathrm{C}$ & 158.1 & $93 \%$ & 158 & $93 \%$ \\
\hline $0.2 \mathrm{C}$ & 144 & $84 \%$ & 148 & $87 \%$ \\
\hline $0.5 \mathrm{C}$ & 133.3 & $78 \%$ & 138 & $81 \%$ \\
\hline $1 \mathrm{C}$ & 86.2 & $51 \%$ & 99 & $58 \%$ \\
\hline
\end{tabular}

As can be seen, the general trend between the two studies ${ }^{114}$ 125 , is the same, however, the comparison is made difficult because of i) the synthesis condition employed, ii) the mixing procedure to obtain the hybrid electrolyte, iii) the different operating conditions (especially the cycling temperature) for the battery testing, and iv) the loading of the electrode is not given in the papers.

Contrary to both pre-cites studies, Zheng et al. ${ }^{128}$ investigated a high amount of LGPS dispersed in little content polymeric matrix. They reported an impressive ionic conductivity recorded of $0.22 \mathrm{mS} . \mathrm{cm}^{-1}$ at $22^{\circ} \mathrm{C}$ for a mixture of LGPS/PEO (70wt.\% LGPS-PEO-LiTFSI). According to the authors, those values can be explained by the good synergy between the PEO and the LGPS obtained via ball milling dispersion enabling better interfacial contact. Additionally, LiTFSI content has a significant effect on LGPS/PEO interfaces formation as the salt can alter the mechanical properties of the composite membrane (affect the flexibility). Unfortunately, the authors did not perform any electrochemical test to check the performance of the HSE, but they conducted $\mathrm{Li}$ plating/stripping test to ensure the compatibility of the hybrid electrolyte with $\mathrm{Li}$ metal. Respectively after, $370 \mathrm{~h}$ and $224 \mathrm{~h}$ the voltage of the cells $\mathrm{Li} / \mathrm{PEO} / \mathrm{Li}$ and $\mathrm{Li} / \mathrm{SE} / \mathrm{Li}$ increase sharply (up to $10 \mathrm{~V} \mathrm{vs.} \mathrm{Li}^{+} / \mathrm{Li}$ ) which testifies that strong electrolyte degradations occurred whereas the cell was stable along $1700 \mathrm{~h}$ for the hybrid electrolyte. They attributed this favourable result to the interface between LGPS/PEO which reduces the direct unstable contact between Li metal and LGPS. Simon et al. ${ }^{107}$ also reported an increase in the ionic conductivity of the HSE made of LGPS/PEO:LiTFSI when increasing LGPS content. They compared, at the same temperature, the ionic conductivity of the HSE (different LGPS wt\%) with the one of the individual materials. They found out that even for a high LGPS content, the ionic conductivity of the HSE remains lower than the one of sulphide-based solid electrolyte. This study suggests that a proper equilibrium should be found between the amount of polymer to be combined with the sulphide-based solid electrolyte to ensure that the ionic conductivity is maintained as high as possible while providing some additional mechanical stability.
Riphaus et al. investigated the chemical stability between LSPS and PEO, used as a barrier to protect the Li metal surface by means of EIS and XPS data. ${ }^{30}$ Time resolved EIS spectra recorded at $40^{\circ} \mathrm{C}$ over a week using stainless steel electrode, shows a steady rise of the cell impedance attributed to the chemical instability at the interface between PEO and LSPS witnessed also by the change in colour of the separator after cell disassembling. ${ }^{60}, 129$ According to the authors, the decomposition could be coming from trap water and/or cell leakage in the PEO that could be released during EIS measurement. They demonstrated simultaneously that the water should be reducing the solid electrolyte, but they observed, at the end, oxidation of the solid electrolyte, discarding water as a probable cause of cell degradation. Further investigations reveal that LSPS decomposes in contact with PEO presumably because of the presence of hydroxyl groups on PEO surface and of LiOH on LSPS surface.

Simon et al. ${ }^{127}$ confirmed, also, the interfacial decomposition reaction occurring between $\mathrm{LPSCl}$ and PEO:LiTFSI by using a layered structure composed of symmetric $\mathrm{Li}$ cell $\mathrm{Li}$ metal/Polymer/LPSCI/Polymer/Li Metal. They reported the formation of an interphase (SPEI for solid polymer electrolyte interface) made of polymer, conductive salt and SE decomposition products at the interface between LPSCI and PEO. By developing a new set-up based on 4-ref cell characterization, they investigated by means of electrochemical impedance spectroscopy, the interfacial resistance of the SPEI and the Li ion charge transfer at the interface between the sulphide solid electrolyte and the polymer. They found out that the interfacial resistance of the SPEI is extremely small indicating a good interface stability between LPSCI and PEO polymer.

Li et al. ${ }^{130}$ investigated an interesting approach about the dispersion of SE into the polymer, a one pot solution based on a mixture of precursors in solution. The obtained film is then easy to scale up, thin and flexible and finally it can reduce the interfacial resistance since the solution can be coated directly on electroactive materials. LPS was selected as the SE and polyethylene sulphide (PES) was then in situ polymerized to create nanocomposite polymer domain. Even if this process looks promising to decrease the interfacial resistance, the synthesis parameters are difficult to control leading to the generation of elemental sulfur in the electrolyte giving then a low ionic conductivity $2.91 \times 10^{-5} \mathrm{~S} \mathrm{~cm}^{-1}$. Nevertheless, the electrochemical tests were performed with LNO-coated NCA particle as positive electrode and Li-In counter electrode. To ensure reasonable ionic conductivity, the tests were performed at $60^{\circ} \mathrm{C}$. As can be seen in Figure 12, the electrochemical performance for NCA coated electrode are good and suffer for only a small fading, showing that this process is a promising approach to better investigate. 

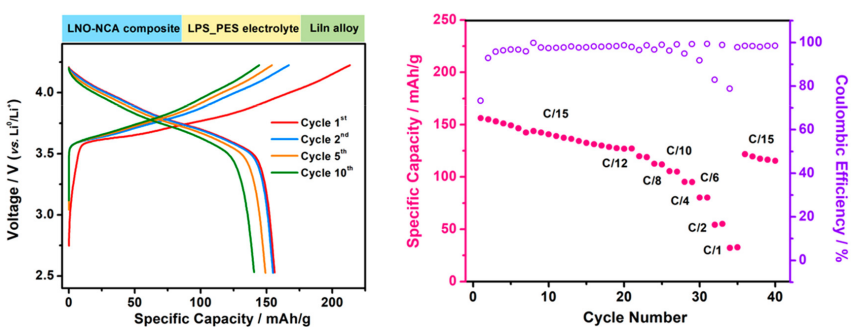

Figure 12. Left) Galvanostatic cycling of the Li-In||SE-SPE||Li-In symmetric cell. Right) rate performance of the Li-In||SEPM||LNO-NCA composite full cell. All cells are tested under $60^{\circ} \mathrm{C}$. Reprinted from ref. ${ }^{130}$. Copyright (2020) American Chemical Society.

\section{Stability at the negative electrode}

In the first part of the paper, we demonstrated that sulphide solid electrolytes have the tendency to decompose strongly once in contact with Li metal. In the case of HSE approach, a surprising interfacial stability is reported at the Li metal electrode. In the case of Chen et al. ${ }^{125}$, the overall interfacial resistance measured by electrochemical impedance spectroscopy (EIS) in symmetric cell, was demonstrated to be very stable for long time ( 27 days) at $40^{\circ} \mathrm{C}$ as indicated by the initial resistance value of the HSE system (freshly assembled cell, $180 \Omega$ ) compared to the polymer alone (PEO-LiTFSI, $913 \Omega$ ).

Chien et al. ${ }^{131}$ investigated the Li distribution at the surface of LGPS particle during cycling and especially the role of the PEO polymer dispersed at the surface of LGPS by using ${ }^{7} \mathrm{Li} \mathrm{MRI}$ (Magnetic Resonance Imaging) technique (Figure 13)132, 133. By performing $\mathrm{Li}$ platting/stripping cycling protocol, they determined that the current densities are higher over time for the cell where LGPS is not protected by the PEO layer, showing the need to protect the surface of LGPS to avoid direct contact with Li metal and ensure long-term cycling stability. They coupled their result to a full investigation performed by EIS showing that the interfacial resistance of LGPS is constantly increasing cycle after cycle as expected from its decomposition once in contact with Li metal. The results obtained from ${ }^{7} \mathrm{Li}$ MRI suggest a Li depletion in LGPS particle between the core (denser) and the surface, which leads to overpotentials in the cell. On the contrary when PEO coated-LGPS is investigated, there is no noticeable gradient in the cell ensuring proper cycling behaviour on long-term. As can be seen in Figure 13, the surface and subsurface of LGPS particles are more deteriorate than their counter part protected with PEO which leads to server interfacial resistance during cycling enhancing the fading of the electrochemical performance.
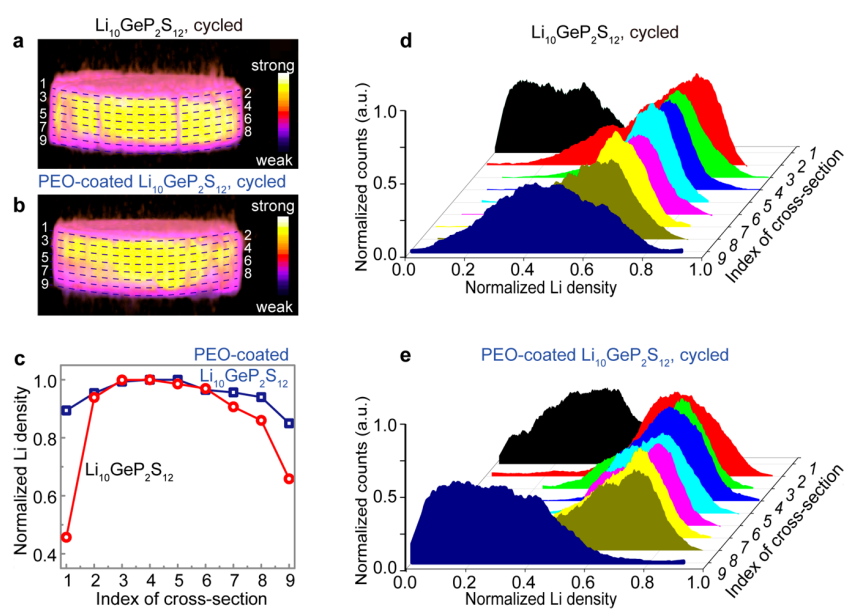

Figure 13. Li density profiles at different depths of electrochemically cycled $\mathrm{Li}_{10} \mathrm{GeP}_{2} \mathrm{~S}_{12}$ pellets. $(\mathrm{a}, \mathrm{b}){ }^{7} \mathrm{Li} 3 \mathrm{D} \mathrm{MRI}$ images of the electrochemically cycled $\mathrm{Li}_{10} \mathrm{GeP}_{2} \mathrm{~S}_{12}$ pellets without and with PEO coating. The color bars indicate the relative $\mathrm{Li}$ concentration, with yellow representing the Li density. (c) Normalized ${ }^{7} \mathrm{Li}$ densities across horizontal layers of the $3 \mathrm{D}$ electrolyte pellet plotted as a function of the layer index shown in $(a, b)$. (d,e) Histograms of normalized Li density at different depths of the cycled $\mathrm{Li}_{10} \mathrm{GeP}_{2} \mathrm{~S}_{12}$ pellets shown in $(\mathrm{a}, \mathrm{b})$, respectively. Reprinted from ref. ${ }^{131}$. Copyright (2020) American Chemical Society.

Simon et al. ${ }^{107}$ investigated the surface reaction occurring at the Li metal interface for a hybrid solid electrolyte consisting of PEO/LiTFSI polymer electrolyte coupled to LPSCI solid electrolyte from $1 \mathrm{wt} . \%$ and $40 \mathrm{wt} . \%$. As expected, and also demonstrated by the authors, the lithium ion transport is highly dependent on the amount of LSPCl, however, a high content of LPSCl is also linked to a high amount of side phases generated during the synthesis process such as $\mathrm{Li}_{2} \mathrm{~S}$, LiF, polysulfides etc. But, adding LPSCI to a PEO based electrolyte leads to stabilise the interfacial resistance at the surface of Li metal electrode by decreasing the SEI resistance and growing rates and modifying its composition (chemical cross-talk between the SEI). The combination of polymer and solid electrolyte is thus a suitable alternative to control the interfaces properties and improve the electrochemical stability.

\section{Ionic transport properties}

In summary, the HSE concept contributes to the stabilization of the whole electrolyte system and leads to reduce the interfacial resistance especially in the Li metal side. However, using HSE raises questions about the ion transport within the hybrid electrolyte layer. At such, the HSE offers, at least, two different ionic conductive networks; i) the one passing through the SE particles and, ii) the one going along the polymer chains. Ideally the ionic transport should be going through both to enhance the performance but it, of course, depends of the ratio between the polymer and the SE. If the ratio is not the good one, the preferential mode of ionic conduction will turn to be a "ceramic in polymer" or a "polymer in ceramic" SE, as evoked here ${ }^{106}$ and depicted in Figure 14. 
(a)

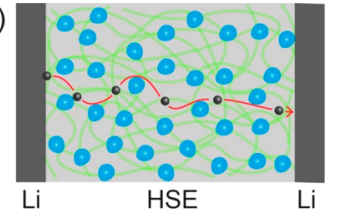

(c)

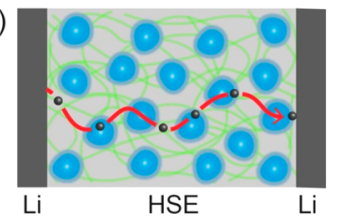

(b)

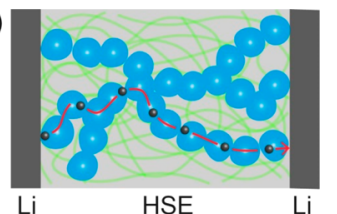

i

HSE

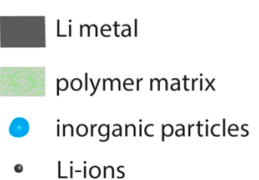

Figure 14. Schematic representation of the Li-ion diffusion pathways in PEO-based HSEs with (a) a small amount of nanofillers, (b) a large fraction of solid electrolyte micro- fillers, and (c) a small fraction of micro-LAGP in the present LAGP-SN-PEO HSE. Reprinted from ref. ${ }^{134}$. Copyright (2020) American Chemical Society.

Zheng et al. ${ }^{128}$ employed high resolution solid state ${ }^{6} \mathrm{Li}$ NMR technique to investigate the ionic transport phenomenon in LGPS-PEO hybrid electrolyte. By deconvoluting the complex ${ }^{6} \mathrm{Li}$ NMR signal and by applying tracker -exchange (6Li and $7 \mathrm{Li}$ ), the interfaces between the polymer and the SE was characterized. They demonstrated that Li ions transport takes place mainly at the interfaces between polymer matrix and SE particles and that a Li depletion is noticed inside LGPS particles, due to its electrochemical decomposition during cycling.

\section{Mechanical stability}

From a mechanical point of view, hybrid solid electrolyte has many advantages. The use of a flexible solid polymer reduces "naturally" the porosity inside the electrolytic layer. Consequently, HSE compact layer contributes to increase the energy density of the cell while facilitating the large-scale production of solid-state batteries. The polymeric matrix used in HSE system limits and absorbs the stress and volume variations inside the solid-state batteries and, thus, hinder the cracks of the SE particles.

To date, Chen et al. ${ }^{125}$ were the only ones providing a proper study on the mechanical properties of a HSE. They recorded the stress-strain curves for their best performing sample consisting of PEO-1wt.\%LGPS-10wt.\%SN (reported earlier in this paper) and compared it to standard PEO and PEO/LGPS samples. The stress-strain curves revealed an elastic behaviour that ends with the breakage of the material for the maximum elongation achievable. For PEO reference electrolyte film, the maximum of tensile strength recorded was $1.5 \mathrm{MPa}$ (corresponding elongation of $400 \%$ ) and it grows to $4.6 \mathrm{MPa}$ (corresponding elongation of $340 \%$ ) with the incorporation of $1 \mathrm{wt} . \%$ LGPS. Once SN is introduced in the sample, the maximum of tensile strength drops to $3.46 \mathrm{MPa}$ (corresponding elongation of $490 \%$ ). Consequently, the addition of LGPS particles into PEO electrolyte makes the HSE more resistant to high stresses (almost three times more) which is compatible with large volume changes and stress occurring inside a solid state batteries. The mechanical properties recorded for the HSE made of sulphide solid electrolyte into a SPE are promising and support the present strategy to limit the SE cracks during cycling. Additionally, those preliminary results also demonstrated that HSE can buffer/ reduce Li dendritic growth. To the best of our knowledge, there is not study dealing with $\mathrm{Li}$ dendrite suppression in the case of HSE made of sulphide solid electrolyte filler.

\section{Conclusions and outlook}

Through this review we demonstrated that the key issues to further develop the solid-state batteries based on sulphidebased electrolytes is the control of the interfacial resistance (at the positive electrode), the protection of the Li metal counter electrode and of the mechanical stability of the stack during cycling. As to know if the mechanical or interfacial stability is the most difficult challenge to address, here are some thoughts.

\section{So, mechanical stability or interfacial stability?}

Through this review, we tried to address the two mains issues related to the solid-state batteries, the mechanical and the interfacial stability. At this stage, it seems that the mechanical stability is more difficult to address than the interfacial one, the reason behind being the knowledge acquired in the last 40 years in the field of Li-ion batteries that could be transferred to solid state batteries technologies. Indeed, we demonstrated that the interfacial issues could be drastically limited by means of coating techniques, as it is commonly accepted in Li-ion batteries technology. On the positive electrode side, a part of the electrolyte decomposition products was found to be reversible and the detrimental effect of the decomposition could be buffered by $\mathrm{LiNbO}_{3}$ coating approach. It leads to stabilize the electrochemical performance of most of the cathode materials providing better long-term cycling stability, but their long-lasting ability needs to be also demonstrated. On the negative electrode side, the Li dendrites issues still remains an open question, as it is the case for conventional Li-ion batteries. Here again, several strategies were employed to passivate properly the Li metal electrode mostly linked to the deposition of $\mathrm{Li}_{3} \mathrm{~N}$ and LiF. Contrary to Li-ion batteries, the $\mathrm{Li}$ metal electrode needs to be properly compressed and embedded in the solid electrolyte, which is, in the case of soft metal like $\mathrm{Li}$, an advantage for manufacture point of view. Of course, this issue is detrimental for the dendrite's formation process, since the surface of the solid electrolyte as well as the one of Li metal should be without any defect. Coating followed by a proper engineering step leading to flatten the Li could avoid or at least buffer the dendrites formation process. Finally, in the case of chemical stability, the solid electrolyte itself could be coated through a core-shell process, which can lead to increase drastically the electrochemical stability windows.

Unfortunately, the mechanical stability is way more difficult to overcome in the case of solid-state batteries because i) already, this issue is not yet solved in the conventional Li-ion batteries, thus a know-how methodology cannot easily be applied, ii) 
there are almost no porosity in the SE and in the composite electrode material, thus the volume changes occurring during cycling cannot be properly compensate, iii) no binder is used in the composite electrode that could compensate the stress/strain issues, iv) the stresses/strains are not constant and homogeneously generated in the cell (because of uniaxial pressure applied in the cell) and, v) the changes occurring at the interfaces during cycling are leading to different stresses/strains. On top of that, the chemical and interfacial stability are influencing the mechanical stability along cycling. As the solid electrolyte will be decomposing, other chemical phases might be formed mostly at the interfaces changing the nature of the chemical bounds, thus, influencing the Young modulus of the solid electrolyte as well as the dispersion of the porosity. Strategies should be then developed in order to mitigate the problems related to the mechanical changes. Actually, several engineering aspects should be considered to improve the mechanical stability, as an example, it is quite difficult to compress the solid electrolyte and composite electrode to $100 \%$, meaning that there are always some residuals porosity. The latter could absorb a part of the mechanical stress, if this porosity is controlled through the electrode and electrolyte stack. Also, the plasticity of the solid electrolyte is a plus value that needs to be considered when we developed sulphide-based solid-state batteries as it can also buffered a part of the stress/strain constraint. As in the case of conventional Li-ion batteries, binder could also be added to the composite electrode, but here, an optimal ratio should be used between the binder (generally an isolating material), the solid electrolyte and the electroactive material to avoid a drastic kinetics limitation. To this point the engineering of the electrode (proper ratio of electroactive materials, binder and carbon additive) needs to be also fully investigated and linked to the interfacial and mechanical data obtained through microstructure tools. Unfortunately, all these pre-cited strategies should be long lasting, since the interfacial stability will be evolving along cycling, new fresh surface with their own stress and strain will be generated leading to additional mechanical stress.

\section{Is hybrid solid state battery the ideal solution for the development of sulphide-based solid-state batteries?}

To the point of view of the mechanical stability, hybrid-based batteries are supposed to be a better alternative, but deeper investigation especially during cycling should be undertaken. If hybrid solid electrolyte looks like the most optimal solution in the paper, there are some big challenges to overcome and lot of questions remaining for their further development. Among the questions to be addressed, there is the chemical/physical affinity between the polymer and the sulphide-based solid electrolyte which implies also the development of a proper methodology to disperse properly the sulphide-based electrolyte into the polymer matrix. The ratio between the polymer and the SE should be of utmost importance as it will govern i) the ionic conductivity and, ii) the mechanical stability. Unfortunately, both of them are antagonist and cannot co-exist simultaneously. Indeed, if we want to privilege the ionic conductivity, the polymer content should be drastically low, leading then to mechanical instability, on the other hand, if we increase the polymer content, then we will be lacking ionic conductivity. Improving the mechanical stability, is unfortunately not improving the chemical stability, as there could have some detrimental degradation reaction at the interface between SE and SPE. Here again the hybrid solid electrolyte batteries could play a role, but not so straightforward. Indeed, the polymer is better in term of electrochemical stability windows, but it requires i) a perfect affinity to the sulphide-based electrolyte, and its derivative generated during decomposition and, ii) temperature to ensure its role of mechanical buffer, while keeping a reasonable ionic conductivity. To buffer all pre-cited issues, the design of the solid-state batteries is crucial. Indeed, a sandwich like cell, i.e. combination of polymer/SE/polymer might be an interesting alternative to ensure a better contact to the Li metal electrode as an example. It could also increase the mechanical stability as the thickness of the solid electrolyte layer, composed of sulphide-based electrolyte could be reduced, avoiding then intense stress/strain. But, the latter alternative will be detrimental to the ionic conductivity except if the cells is targeting high temperature cycling. In this particular research area, investigation and studies are so far missing to ensure a proper understanding of the conduction mechanisms through the cell and its components but also of at the interfacial level to understand the local chemistry behind the reaction mechanism. Finally, the mechanical stability should be thoroughly investigated to ensure that the polymer is indeed playing a role of buffer agent to the strain/stress constraints.

Operando techniques should be then heavily used to answer properly to those precited concerns as only a very detailed understanding of the overall and local mechanisms could help to develop a "solid" state battery.

\section{Conflicts of interest}

There are no conflicts to declare.

\section{References}

1. T. Famprikis, P. Canepa, J. A. Dawson, M. S. Islam and C. Masquelier, Nature Materials, 2019, DOI: 10.1038/s41563019-0431-3.

2. X. Judez, G. G. Eshetu, C. Li, L. M. Rodriguez-Martinez, H. Zhang and M. Armand, Joule, 2018, 2, 2208-2224.

3. V. Viallet, V. Seznec, A. Hayashi, M. Tatsumisago and A. Pradel, in Springer Handbook of Glass, eds. J. D. M. eds, J.Hu and L. Calvez, Springer International Publishing AG, 2019, pp. 1707-1764.

4. Z. Zeng, B. Wu, L. Xiao, X. Jiang, Y. Chen, X. Ai, H. Yang and Y. Cao, Journal of Power Sources, 2015, 279, 6-12.

5. S. Ohno, A. Banik, G. F. Dewald, M. A. Kraft, T. Krauskopf, N. Minafra, P. Till, M. Weiss and W. G. Zeier, Progress in Energy, 2020, 2, 022001. 
6.

J. C. Bachman, S. Muy, A. Grimaud, H.-H. Chang, N. Pour, S. F. Lux, O. Paschos, F. Maglia, S. Lupart, P. Lamp, L. Giordano and Y. Shao-Horn, Chemical Reviews, 2016, 116, 140-162.

7. Y. Kato, S. Hori, T. Saito, K. Suzuki, M. Hirayama, A. Mitsui, M. Yonemura, H. Iba and R. Kanno, Nature Energy, 2016, 1, 16030.

8. N. Kamaya, K. Homma, Y. Yamakawa, M. Hirayama, R. Kanno, M. Yonemura, T. Kamiyama, Y. Kato, S. Hama, K. Kawamoto and A. Mitsui, Nature Materials, 2011, 10, 682686.

9. M. Tatsumisago and A. Hayashi, Solid State lonics, 2012, 225, 342-345.

10. Y. S. Jung, D. Y. Oh, Y. J. Nam and K. H. Park, Israel Journal of Chemistry, 2015, 55, 472-485.

11. C. Sun, J. Liu, Y. Gong, D. P. Wilkinson and J. Zhang, Nano Energy, 2017, 33, 363-386.

12. R. Pfenninger, M. Struzik, I. Garbayo, E. Stilp and J. L. M. Rupp, Nature Energy, 2019, 4, 475-483.

13. S. Chen, D. Xie, G. Liu, J. P. Mwizerwa, Q. Zhang, Y. Zhao, X. Xu and X. Yao, Energy Storage Materials, 2018, 14, 58-74. S. Ohno, T. Bernges, J. Buchheim, M. Duchardt, A.-K. Hatz, M. A. Kraft, H. Kwak, A. L. Santhosha, Z. Liu, N. Minafra, F. Tsuji, A. Sakuda, R. Schlem, S. Xiong, Z. Zhang, P. Adelhelm, H. Chen, A. Hayashi, Y. S. Jung, B. V. Lotsch, B. Roling, N. M. Vargas-Barbosa and W. G. Zeier, ACS Energy Letters, 2020, DOI: 10.1021/acsenergylett.9b02764, 910-915.

15. M. Ghidiu, J. Ruhl, S. P. Culver and W. G. Zeier, Journal of Materials Chemistry A, 2019, 7, 17735-17753.

16. A. Gautam, M. Sadowski, N. Prinz, H. Eickhoff, N. Minafra, M. Ghidiu, S. P. Culver, K. Albe, T. F. Fässler, M. Zobel and W. G. Zeier, Chemistry of Materials, 2019, 31, 1017810185.

17. M. Tachez, J.-P. Malugani, R. Mercier and G. Robert, Solid State lonics, 1984, 14, 181-185.

18. K. Homma, M. Yonemura, T. Kobayashi, M. Nagao, M. Hirayama and R. Kanno, Solid State lonics, 2011, 182, 5358.

19. H. Yamane, M. Shibata, Y. Shimane, T. Junke, Y. Seino, S. Adams, K. Minami, A. Hayashi and M. Tatsumisago, Solid State lonics, 2007, 178, 1163-1167.

20. F. Mizuno, A. Hayashi, K. Tadanaga and M. Tatsumisago, Solid State lonics, 2006, 177, 2721-2725.

21. H.-J. Deiseroth, S.-T. Kong, H. Eckert, J. Vannahme, C. Reiner, T. Zaiß and M. Schlosser, Angewandte Chemie International Edition, 2008, 47, 755-758.

22. P. Bron, S. Johansson, K. Zick, J. Schmedt auf der Günne, S. Dehnen and B. Roling, Journal of the American Chemical Society, 2013, 135, 15694-15697.

23. N. M. Vargas-Barbosa and B. Roling, ChemElectroChem, 2020, 7, 367-385.

24. N. Riphaus, P. Strobl, B. Stiaszny, T. Zinkevich, M. Yavuz, J. Schnell, S. Indris, H. A. Gasteiger and S. J. Sedlmaier, Journal of The Electrochemical Society, 2018, 165, A3993A3999.

25. K. Yoon, J.-J. Kim, W. M. Seong, M. H. Lee and K. Kang, Scientific Reports, 2018, 8, 8066.

26. F. Hao, F. Han, Y. Liang, C. Wang and Y. Yao, MRS Bulletin, 2018, 43, 775-781.

27. L. Xu, S. Tang, Y. Cheng, K. Wang, J. Liang, C. Liu, Y.-C. Cao, F. Wei and L. Mai, Joule, 2018, 2, 1991-2015.

28. R. C. Xu, X. H. Xia, S. Z. Zhang, D. Xie, X. L. Wang and J. P. Tu, Electrochimica Acta, 2018, 284, 177-187.
29.

A. C. Luntz, J. Voss and K. Reuter, The Journal of Physical Chemistry Letters, 2015, 6, 4599-4604.

30. N. Riphaus, B. Stiaszny, H. Beyer, S. Indris, H. A. Gasteiger and S. J. Sedlmaier, Journal of The Electrochemical Society, 2019, 166, A975-A983.

31. R. Chen, Q. Li, X. Yu, L. Chen and H. Li, Chemical Reviews, 2019, DOI: 10.1021/acs.chemrev.9b00268.

32. A. Kato, M. Nose, M. Yamamoto, A. Sakuda, A. Hayashi and M. Tatsumisago, Journal of the Ceramic Society of Japan, 2018, 126, 719-727.

G. Bucci, B. Talamini, A. Renuka Balakrishna, Y.-M. Chiang and W. C. Carter, Physical Review Materials, 2018, 2, 105407.

34. K. Fu, Y. Gong, B. Liu, Y. Zhu, S. Xu, Y. Yao, W. Luo, C. Wang, S. D. Lacey, J. Dai, Y. Chen, Y. Mo, E. Wachsman and L. Hu, Science Advances, 2017, 3, e1601659.

C. Hou, X.-Y. Lang, G.-F. Han, Y.-Q. Li, L. Zhao, Z. Wen, Y.-F. Zhu, M. Zhao, J.-C. Li, J.-S. Lian and Q. Jiang, Scientific Reports, 2013, 3, 2878.

36. Y. Zhu, X. He and Y. Mo, ACS Applied Materials \& Interfaces, 2015, 7, 23685-23693.

37. G. F. Dewald, S. Ohno, M. A. Kraft, R. Koerver, P. Till, N. M. Vargas-Barbosa, J. Janek and W. G. Zeier, Chemistry of Materials, 2019, DOI: 10.1021/acs.chemmater.9b01550.

38. F. Wu, W. Fitzhugh, L. Ye, J. Ning and X. Li, Nature Communications, 2018, 9, 4037.

39. Q. Zhang, D. Cao, Y. Ma, A. Natan, P. Aurora and H. Zhu, Advanced Materials, 2019, 31, 1901131.

40. C. Dietrich, R. Koerver, M. W. Gaultois, G. Kieslich, G. Cibin, J. Janek and W. G. Zeier, Physical Chemistry Chemical Physics, 2018, 20, 20088-20095.

41. F. Han, T. Gao, Y. Zhu, K. J. Gaskell and C. Wang, Advanced Materials, 2015, 27, 3473-3483.

42. D. H. S. Tan, E. A. Wu, H. Nguyen, Z. Chen, M. A. T. Marple, J.-M. Doux, X. Wang, H. Yang, A. Banerjee and Y. S. Meng, ACS Energy Letters, 2019, 4, 2418-2427.

43. A. Gurung, J. Pokharel, A. Baniya, R. Pathak, K. Chen, B. S. Lamsal, N. Ghimire, W.-H. Zhang, Y. Zhou and Q. Qiao, Sustainable Energy \& Fuels, 2019, DOI: 10.1039/C9SE00549H.

44. J. Auvergniot, A. Cassel, J.-B. Ledeuil, V. Viallet, V. Seznec and R. Dedryvère, Chemistry of Materials, 2017, 29, 38833890.

45. X. Wu, C. Villevieille, P. Novak and M. El Kazzi, Physical Chemistry Chemical Physics, 2018, 20, 11123-11129.

46. M. Otoyama, Y. Ito, A. Hayashi and M. Tatsumisago, Journal of Power Sources, 2016, 302, 419-425.

47. J. Haruyama, K. Sodeyama, L. Han, K. Takada and Y. Tateyama, Chemistry of Materials, 2014, 26, 4248-4255.

48. H. Kitaura, A. Hayashi, T. Ohtomo, S. Hama and M. Tatsumisago, Journal of Materials Chemistry, 2011, 21, 118-124.

49. N. Ohta, K. Takada, I. Sakaguchi, L. Zhang, R. Ma, K. Fukuda, M. Osada and T. Sasaki, Electrochemistry Communications, 2007, 9, 1486-1490.

50. N. Ohta, K. Takada, L. Zhang, R. Ma, M. Osada and T. Sasaki, Advanced Materials, 2006, 18, 2226-2229.

51. W. Zhang, F. H. Richter, S. P. Culver, T. Leichtweiss, J. G. Lozano, C. Dietrich, P. G. Bruce, W. G. Zeier and J. Janek, ACS Applied Materials \& Interfaces, 2018, 10, 2222622236. 
52.

A. Sakuda, H. Kitaura, A. Hayashi, K. Tadanaga and M. Tatsumisago, Journal of The Electrochemical Society, 2009, 156, A27-A32.

53. C. Vinado, S. Wang, Y. He, X. Xiao, Y. Li, C. Wang and J. Yang, Journal of Power Sources, 2018, 396, 824-830.

54. K. Takada, Langmuir, 2013, 29, 7538-7541.

55. A. Hayashi, Y. Nishio, H. Kitaura and M. Tatsumisago, Electrochemistry Communications, 2008, 10, 1860-1863.

56. S. P. Culver, R. Koerver, W. G. Zeier and J. Janek, Advanced Energy Materials, 2019, 9, 1900626.

57. M. Du, K. Liao, Q. Lu and Z. Shao, Energy \& Environmental Science, 2019, 12, 1780-1804.

58. K. Takada, N. Ohta, L. Zhang, X. Xu, B. T. Hang, T. Ohnishi, M. Osada and T. Sasaki, Solid State Ionics, 2012, 225, 594597.

59. S. Wang, X. Xu, X. Zhang, C. Xin, B. Xu, L. Li, Y.-H. Lin, Y. Shen, B. Li and C.-W. Nan, Journal of Materials Chemistry A, 2019, 7, 18612-18618.

60. R. Koerver, I. Aygün, T. Leichtweiß, C. Dietrich, W. Zhang, J. O. Binder, P. Hartmann, W. G. Zeier and J. Janek, Chemistry of Materials, 2017, 29, 5574-5582.

61. R. Koerver, F. Walther, I. Aygün, J. Sann, C. Dietrich, W. G. Zeier and J. Janek, Journal of Materials Chemistry A, 2017, 5, 22750-22760.

62. S.-K. Jung, H. Gwon, S.-S. Lee, H. Kim, J. C. Lee, J. G. Chung, S. Y. Park, Y. Aihara and D. Im, Journal of Materials Chemistry A, 2019, 7, 22967-22976.

63. S. Choi, B.-N. Yun, W. D. Jung, T. H. Kim, K.-Y. Chung, J.-W. Son, B.-I. Sang, H.-G. Jung and H. Kim, Scripta Materialia, 2019, 165, 10-14.

64. H. Maleki Kheimeh Sari and X. Li, Advanced Energy Materials, 2019, 9, 1901597.

65. S. S. Zhang, Energy Storage Materials, 2019, DOI: https://doi.org/10.1016/i.ensm.2019.08.013.

66. A. Y. Kim, F. Strauss, T. Bartsch, J. H. Teo, T. Hatsukade, A. Mazilkin, J. Janek, P. Hartmann and T. Brezesinski, Chemistry of Materials, 2019, DOI: 10.1021/acs.chemmater.9b02947.

67. A. Neumann, S. Randau, K. Becker-Steinberger, T. Danner, S. Hein, Z. Ning, J. Marrow, F. H. Richter, J. Janek and A. Latz, ACS Applied Materials \& Interfaces, 2020, 12, 92779291.

68. X. Wu, J. Billaud, I. Jerjen, F. Marone, Y. Ishihara, M. Adachi, Y. Adachi, C. Villevieille and Y. Kato, Advanced Energy Materials, 2019, 9, 1901547.

69. X. Li, Z. Ren, M. Norouzi Banis, S. Deng, Y. Zhao, Q. Sun, C. Wang, X. Yang, W. Li, J. Liang, X. Li, Y. Sun, K. Adair, R. Li, Y. $\mathrm{Hu}, \mathrm{T}$.-K. Sham, H. Huang, L. Zhang, S. Lu, J. Luo and X. Sun, ACS Energy Letters, 2019, 4, 2480-2488.

70. J. Zhang, H. Zhong, C. Zheng, Y. Xia, C. Liang, H. Huang, Y. Gan, X. Tao and W. Zhang, Journal of Power Sources, 2018, 391, 73-79.

71. A. Sakuda, T. Takeuchi and H. Kobayashi, Solid State lonics, 2016, 285, 112-117.

72. F. Strauss, T. Bartsch, L. de Biasi, A. Y. Kim, J. Janek, P. Hartmann and T. Brezesinski, ACS Energy Letters, 2018, 3, 992-996.

73. X. Wu, M. El Kazzi and C. Villevieille, Journal of Electroceramics, 2017, 38, 207-214.

74. X. Wu, C. Villevieille, P. Novák and M. El Kazzi, Journal of Materials Chemistry A, 2020, DOI: 10.1039/C9TA14147B.
75.

\section{6.}

77.

78.

\section{1.}

\section{2.}

\section{3.}

84.

85.

86.
M. Fantauzzi, B. Elsener, D. Atzei, A. Rigoldi and A. Rossi, RSC Advances, 2015, 5, 75953-75963.

A. L. Santhosha, L. Medenbach, J. R. Buchheim and P. Adelhelm, Batteries \& Supercaps, 2019, 2, 524-529.

L. E. Camacho-Forero and P. B. Balbuena, Journal of Power Sources, 2018, 396, 782-790.

S. Wenzel, S. Randau, T. Leichtweiß, D. A. Weber, J. Sann, W. G. Zeier and J. Janek, Chemistry of Materials, 2016, 28, 2400-2407.

S. Wenzel, D. A. Weber, T. Leichtweiss, M. R. Busche, J. Sann and J. Janek, Solid State Ionics, 2016, 286, 24-33.

S. Wenzel, S. J. Sedlmaier, C. Dietrich, W. G. Zeier and J. Janek, Solid State lonics, 2018, 318, 102-112.

R. Xu, F. Han, X. Ji, X. Fan, J. Tu and C. Wang, Nano Energy, 2018, 53, 958-966.

B. Chen, C. Xu, H. Wang and J. Zhou, Current Applied Physics, 2019, 19, 149-154.

A. Kızılaslan and H. Akbulut, ChemPlusChem, 2019, 84, 183189.

Y. Zhu, X. He and Y. Mo, Advanced Science, 2017, 4, 1600517.

F. Zhao, Q. Sun, C. Yu, S. Zhang, K. R. Adair, S. Wang, Y. Liu, Y. Zhao, J. Liang, C. Wang, X. Li, X. Li, W. Xia, R. Li, H. Huang, L. Zhang, S. Zhao, S. Lu and X. Sun, ACS Energy Letters, 2020, DOI: 10.1021/acsenergylett.0c00207.

L. Sang, K. L. Bassett, F. C. Castro, M. J. Young, L. Chen, R. T. Haasch, J. W. Elam, V. P. Dravid, R. G. Nuzzo and A. A. Gewirth, Chemistry of Materials, 2018, 30, 8747-8756.

J. A. Lewis, F. J. Q. Cortes, M. G. Boebinger, J. Tippens, T. S. Marchese, N. Kondekar, X. Liu, M. Chi and M. T. McDowell, ACS Energy Letters, 2019, 4, 591-599.

J. A. Lewis, J. Tippens, F. J. Q. Cortes and M. T. McDowell, Trends in Chemistry, 2019, 1, 845-857.

W. Zhang, D. Schröder, T. Arlt, I. Manke, R. Koerver, R. Pinedo, D. A. Weber, J. Sann, W. G. Zeier and J. Janek, Journal of Materials Chemistry A, 2017, 5, 9929-9936.

J. M. Whiteley, J. W. Kim, C. S. Kang, J. S. Cho, K. H. Oh and S.-H. Lee, Journal of The Electrochemical Society, 2015, 162, A711-A715.

C. Villevieille, M. Ebner, J. L. Gomez-Camer, F. Marone, P. Novak and V. Wood, Advanced Materials, 2015, 27, 1676+ .

A. Kato, M. Yamamoto, A. Sakuda, A. Hayashi and M. Tatsumisago, ACS Applied Energy Materials, 2018, 1, 10021007.

D. Hlushkou, A. E. Reising, N. Kaiser, S. Spannenberger, S. Schlabach, Y. Kato, B. Roling and U. Tallarek, Journal of

Power Sources, 2018, 396, 363-370.
R. Koerver, W. Zhang, L. de Biasi, S. Schweidler, A. O. Kondrakov, S. Kolling, T. Brezesinski, P. Hartmann, W. G. Zeier and J. Janek, Energy \& Environmental Science, 2018, 11, 2142-2158.

W. Fitzhugh, L. Ye and X. Li, Journal of Materials Chemistry A, 2019, 7, 23604-23627.

F. Han, Y. Zhu, X. He, Y. Mo and C. Wang, Advanced Energy Materials, 2016, 6, 1501590.

W. Fitzhugh, F. Wu, L. Ye, H. Su and X. Li, Small, 2019, 15, 1901470.

K. Suzuki, D. Kato, K. Hara, T.-a. Yano, M. Hirayama, M. Hara and R. Kanno, Electrochemistry, 2017, 86, 1-5. 
99. Y. Aihara, S. Ito, R. Omoda, T. Yamada, S. Fujiki, T. Watanabe, Y. Park and S. Doo, Frontiers in Energy Research, 2016, 4.

100. S. Ohno, R. Koerver, G. Dewald, C. Rosenbach, P. Titscher, D. Steckermeier, A. Kwade, J. Janek and W. G. Zeier, Chemistry of Materials, 2019, 31, 2930-2940.

101. W. Zhang, T. Leichtweiß, S. P. Culver, R. Koerver, D. Das, D. A. Weber, W. G. Zeier and J. Janek, ACS Applied Materials \& Interfaces, 2017, 9, 35888-35896.

102. J. B. Goodenough and P. Singh, Journal of The Electrochemical Society, 2015, 162, A2387-A2392.

103. T. Shodai, B. B. Owens, H. Ohtsuka and J. i. Yamaki, Journal of The Electrochemical Society, 1994, 141, 2611-2614.

104. H. H. Sumathipala, J. Hassoun, S. Panero and B. Scrosati, Journal of Applied Electrochemistry, 2008, 38, 39-42.

105. Y.-C. Jung, M.-S. Park, D.-H. Kim, M. Ue, A. Eftekhari and D.W. Kim, Scientific Reports, 2017, 7, 17482.

106. L. Chen, Y. Li, S.-P. Li, L.-Z. Fan, C.-W. Nan and J. B. Goodenough, Nano Energy, 2018, 46, 176-184.

107. F. J. Simon, M. Hanauer, F. H. Richter and J. Janek, ACS Applied Materials \& Interfaces, 2020, 12, 11713-11723.

108. Z. Xue, D. He and X. Xie, Journal of Materials Chemistry A, 2015, 3, 19218-19253.

109. S. Srivastava, J. L. Schaefer, Z. Yang, Z. Tu and L. A. Archer, Advanced Materials, 2014, 26, 201-234.

110. P.-J. Alarco, Y. Abu-Lebdeh, A. Abouimrane and M. Armand, Nature Materials, 2004, 3, 476-481.

111. L.-Z. Fan and J. Maier, Electrochemistry Communications, 2006, 8, 1753-1756.

112. J. E. Weston and B. C. H. Steele, Solid State lonics, 1982, 7, 75-79.

113. S. Yu, S. Schmohl, Z. Liu, M. Hoffmeyer, N. Schön, F. Hausen, H. Tempel, H. Kungl, H. D. Wiemhöfer and R. A. Eichel, Journal of Materials Chemistry A, 2019, 7, 38823894.

114. Y. Zhao, C. Wu, G. Peng, X. Chen, X. Yao, Y. Bai, F. Wu, S. Chen and X. Xu, Journal of Power Sources, 2016, 301, 4753.

115. W. E. Tenhaeff, X. Yu, K. Hong, K. A. Perry and N. J. Dudney, Journal of The Electrochemical Society, 2011, 158, A1143A1149.

116. F. Croce, G. B. Appetecchi, L. Persi and B. Scrosati, Nature, 1998, 394, 456-458.

117. J. Paulsdorf, N. Kaskhedikar, M. Burjanadze, S. Obeidi, N. A. Stolwijk, D. Wilmer and H. D. Wiemhöfer, Chemistry of Materials, 2006, 18, 1281-1288.

118. S. Jankowsky, M. M. Hiller, O. Fromm, M. Winter and H. D. Wiemhöfer, Electrochimica Acta, 2015, 155, 364-371.

119. A. Varzi, R. Raccichini, S. Passerini and B. Scrosati, Journal of Materials Chemistry A, 2016, 4, 17251-17259.

120. C. Xu, B. Sun, T. Gustafsson, K. Edström, D. Brandell and M. Hahlin, Journal of Materials Chemistry A, 2014, 2, 72567264.

121. J. G. Kim, B. Son, S. Mukherjee, N. Schuppert, A. Bates, O. Kwon, M. J. Choi, H. Y. Chung and S. Park, Journal of Power Sources, 2015, 282, 299-322.

122. K.-i. Chung, W.-S. Kim and Y.-K. Choi, Journal of Electroanalytical Chemistry, 2004, 566, 263-267.

123. M. Ogawa, R. Kanda, K. Yoshida, T. Uemura and K. Harada, Journal of Power Sources, 2012, 205, 487-490.

$124 . \quad$ S.-D. Lee, K.-N. Jung, H. Kim, H.-S. Shin, S.-W. Song, M.-S. Park and J.-W. Lee, ChemSusChem, 2017, 10, 2175-2181.
125.

126.

and X. Xu, Electrochimica Acta, 2016, 210, 905-914.

D. Y. Oh, Y. J. Nam, K. H. Park, S. H. Jung, S.-J. Cho, Y. K. Kim, Y.-G. Lee, S.-Y. Lee and Y. S. Jung, Advanced Energy Materials, 2015, 5, 1500865.

127. F. J. Simon, M. Hanauer, A. Henss, F. H. Richter and J. Janek, ACS Applied Materials \& Interfaces, 2019, 11, 4218642196.

128. J. Zheng, P. Wang, H. Liu and Y.-Y. Hu, ACS Applied Energy Materials, 2019, 2, 1452-1459.

129. R. Blanga, M. Goor, L. Burstein, Y. Rosenberg, A. Gladkich, D. Logvinuk, I. Shechtman and D. Golodnitsky, Journal of Solid State Electrochemistry, 2016, 20, 3393-3404.

130. Y. Li, X. Wang, H. Zhou, X. Xing, A. Banerjee, J. Holoubek, H. Liu, Y. S. Meng and P. Liu, ACS Energy Letters, 2020, DOI: 10.1021/acsenergylett.0c00040, 955-961.

131. P.-H. Chien, X. Feng, M. Tang, J. T. Rosenberg, S. O'Neill, J. Zheng, S. C. Grant and Y.-Y. Hu, The Journal of Physical Chemistry Letters, 2018, 9, 1990-1998.

132. S. Chandrashekar, N. M. Trease, H. J. Chang, L.-S. Du, C. P. Grey and A. Jerschow, Nature Materials, 2012, 11, 311315.

133. S. A. Krachkovskiy, J. D. Bazak, P. Werhun, B. J. Balcom, I. C. Halalay and G. R. Goward, Journal of the American Chemical Society, 2016, 138, 7992-7999.

M. Liu, Z. Cheng, S. Ganapathy, C. Wang, L. A. Haverkate, M. Tułodziecki, S. Unnikrishnan and M. Wagemaker, ACS Energy Letters, 2019, 4, 2336-2342. 